\title{
On Probabilistic Alpha-Fuzzy Fixed Points and Related Convergence Results in Probabilistic Metric and Menger Spaces under Some Pompeiu-Hausdorff-Like Probabilistic Contractive Conditions
}

\author{
M. De la Sen \\ Institute of Research and Development of Processes IIDP, Faculty of Science and Technology, University of the Basque Country, \\ Barrio Sarriena, Biscay, 48940 Leioa, Spain \\ Correspondence should be addressed to M. De la Sen; manuel.delasen@ehu.es
}

Received 10 August 2015; Revised 24 September 2015; Accepted 13 October 2015

Academic Editor: Pasquale Vetro

Copyright (c) 2015 M. De la Sen. This is an open access article distributed under the Creative Commons Attribution License, which permits unrestricted use, distribution, and reproduction in any medium, provided the original work is properly cited.

In the framework of complete probabilistic metric spaces and, in particular, in probabilistic Menger spaces, this paper investigates some relevant properties of convergence of sequences to probabilistic $\alpha$-fuzzy fixed points under some types of probabilistic contractive conditions.

\section{Introduction}

Fixed point theory is an important tool to investigate the convergence of sequences to limits and unique limits in metric spaces and normed spaces. See, for instance, [1-34] and the wide list of references cited in those papers. In particular, fixed point theory is also a relevant tool to investigate iterative schemes and stability theory of continuous-time and discretetime dynamic systems, boundedness of the trajectory solutions, stability of equilibrium points, convergence to stable equilibrium points, and the existence oscillatory solution trajectories [15-17, 23, 35]. See also references therein. On the other hand, fixed point theory is nowadays receiving important research attention in the framework of probabilistic metric spaces. See, for instance, $[25,26,28,33,34,36-$ 38 ] and references therein. It has also to be pointed out that Menger probabilistic metric spaces are a special class of the wide class of probabilistic metric spaces which are endowed with a triangular norm $[25,26,28,33,34,36,37]$ and which are very useful in the context of fixed point theory. Note that the triangular norm plays a close role to that of the norm in normed spaces. In probabilistic metric spaces, the deterministic notion of distance is revisited as being probabilistic in the sense that, given any two points $x$ and $y$ of a certain metric space, a measure of the distance between them is a probabilistic metric $F_{x, y}(t)$, rather than the deterministic distance $d(x, y)$, which is interpreted as the probability of the distance between $x$ and $y$ being less than $t(t>0)[33,34]$.

Fixed point theorems in complete Menger spaces for probabilistic concepts of $B$ and $C$-contractions can be found in [33] together with a new notion of contraction, referred to as $(\Psi, C)$-contraction. Such a contraction was proved to be useful for multivalued mappings while it generalizes the previous concept of $C$-contraction. On the other hand, fuzzy metric spaces have been investigated more recently and some ad hoc versions of fixed point theorems have been obtained in that framework. See, for instance, $[4-6,32]$ and some references therein.

This paper investigates some relevant properties of convergence of sequences to the so-called and defined probabilistic $\alpha$-fuzzy fixed points under some types of probabilistic contractive conditions. The concept of probabilistic $\alpha$-fuzzy fixed point is defined as an "ad hoc" conceptual extension of that of $\alpha$-fuzzy fixed points of $[6,32]$ and it is oriented to the derivation of convergence properties of fuzzy mappings defined on probabilistic metric spaces and, in particular, in probabilistic Menger spaces. 
Notation, Preliminaries, and Some Basic Concepts. Denote by $\mathbf{R}_{+}=\{z \in \mathbf{R}: z>0\}, \mathbf{R}_{0+}=\mathbf{R}_{+} \cup\{0\}, \mathbf{Z}_{+}=\{z \in$ $\mathbf{Z}: z>0\}, \mathbf{Z}_{0+}=\mathbf{Z}_{+} \cup\{0\}, \bar{n}=\{1,2, \ldots, n\}$, and denote by $\Delta_{F}$ (a common used name for this class being $D^{+}$) the set of probability distribution functions $F: \mathbf{R} \rightarrow[0,1]$, [1], which are nondecreasing and left-continuous such that $F(0)=\inf _{t \in \mathbf{R}} F(t)=0$ and $\sup _{t \in \mathbf{R}} F(t)=1$. Let $X$ be a nonempty set and let the probabilistic metric (or distance) $\mathbf{F}: X \times X \rightarrow \Delta_{\mathbf{F}}$ be a symmetric mapping from $X \times X$ to $\Delta_{\mathrm{F}}$, where $X$ is an abstract set, to the set of distance distribution functions $\Delta_{\mathbf{F}}$ of the form $F: \mathbf{R} \rightarrow[0,1]$ which are functions of elements $F_{x, y}$ for every $(x, y) \in X \times X$. Then, the ordered pair $(X, \mathbf{F})$ is a probabilistic metric space $(\mathrm{PM})$ $[16,28,33,34,36-38]$ if the following constraints hold:

(1) $\forall x, y \in X\left(\left(F_{x, y}(t)=1 ; \forall t \in \mathbf{R}_{+}\right) \Leftrightarrow(x=y)\right)$, equivalently,

$$
F_{x, y}(t)=F(t) \Longleftrightarrow x=y,
$$

where $F \in \Delta_{\mathbf{F}}$ is defined by

$$
F(t)= \begin{cases}0, & \text { if } t \leq 0 \\ 1, & \text { if } t>0\end{cases}
$$

(2) $F_{x, y}(t)=F_{y, x}(t) ; \forall x, y \in X, \forall t \in \mathbf{R}$

(3)

$$
\begin{aligned}
& \forall x, y, z \in X ; \forall t_{1}, t_{2} \in \mathbf{R}_{+} \\
& \quad\left(\left(F_{x, y}\left(t_{1}\right)=F_{y, z}\left(t_{2}\right)=1\right) \Longrightarrow\left(F_{x, z}\left(t_{1}+t_{2}\right)=1\right)\right) .
\end{aligned}
$$

A particular distance distribution function $F_{x, y} \in \Delta_{\mathrm{F}}$ is a probabilistic metric (or distance) which takes values $F_{x, y}(t)$ identified with a probability distance density function $F$ : $\mathbf{R} \rightarrow[0,1]$ in the set of all the distance distribution functions $\Delta_{\mathrm{F}}$.

A Menger PM-space is a triplet $(X, \mathbf{F}, \Delta)$, where $(X, \mathbf{F})$ is a PM-space which satisfies

$$
\begin{aligned}
F_{x, y}\left(t_{1}+t_{2}\right) \geq \Delta\left(F_{x, z}\left(t_{1}\right),\right. & \left.F_{z, y}\left(t_{2}\right)\right) \\
& \forall x, y, z \in X, \forall t_{1}, t_{2} \in \mathbf{R}_{0+}
\end{aligned}
$$

under $\Delta:[0,1] \times[0,1] \rightarrow[0,1]$ which is a $t$-norm (or triangular norm) belonging to the set $\mathbf{T}$ of $t$-norms which satisfy the following properties:

(1) $\Delta(a, 1)=a$,

(2) $\Delta(a, b)=\Delta(b, a)$,

(3) $\Delta(c, d) \geq \Delta(a, b)$ if $c \geq a, d \geq b$,

(4)

$$
\Delta(\Delta(a, b), c)=\Delta(a, \Delta(b, c)) .
$$

A property which follows from the above ones is $\Delta(a, 0)=0$ for $a \in[0,1]$. Typical continuous $t$-norms are the minimum $t$-norm defined by $\Delta_{M}(a, b)=\min (a, b)$, the product $t$-norm defined by $\Delta_{P}(a, b)=a \cdot b$, and the Lukasiewicz $t$-norm defined by $\Delta_{L}(a, b)=\max (a+b-1,0)$ which are related by the inequalities $\Delta_{L} \leq \Delta_{P} \leq \Delta_{M}$. (i) The triplet $(X, \mathbf{F}, \Delta)$ is a Menger space, where $(X, \mathbf{F})$ is a PM-space and $\Delta:[0,1] \times[0,1] \rightarrow[0,1]$ is a triangular norm, which satisfies the inequality $F_{x, z}(t+$ $s) \geq \Delta\left(F_{x, y}(t), F_{y, z}(s)\right) ; \forall x, y, z \in X ; \forall t, s \in \mathbf{R}_{+}$.

(ii) $\Delta_{M}:[0,1] \times[0,1] \rightarrow[0,1]$ is the minimum triangular norm defined by $\Delta_{M}(a, b)=\min (a, b)$.

(iii) A sequence $\left\{x_{n}\right\} \subseteq X$ in a probabilistic space $(X, \mathbf{F})$ is said to be

(1) convergent to a point $x \in X$, denoted by $\left\{x_{n}\right\} \rightarrow$ $x$ (a.s.), if for every $\varepsilon \in \mathbf{R}_{+}$and $\lambda \in(0,1)$, there exists some $N=N(\varepsilon, \lambda) \in \mathbf{Z}_{0+}$ such that

$$
F_{x_{n}, x}(\varepsilon)>1-\lambda ; \quad \forall n\left(\in \mathbf{Z}_{0+}\right) \geq N,
$$

(2) Cauchy if for every $\varepsilon \in \mathbf{R}_{+}$and $\lambda \in(0,1)$, there exists some $N=N(\varepsilon, \lambda) \in \mathbf{Z}_{0+}$ such that

$$
F_{x_{n}, x_{m}}(\varepsilon)>1-\lambda ; \quad \forall n, m\left(\in \mathbf{Z}_{0+}\right) \geq N .
$$

A PM-space $(X, \mathbf{F})$ is complete if every Cauchy sequence is convergent.

\section{Concepts and Results on Probabilistic $\alpha$-Fuzzy Fixed Points}

Let $A, B$ be nonempty subsets of an abstract nonempty set $X$. Then the probabilistic point-to-set distance mapping $\mathbf{F}$ : $X \times A \rightarrow \Delta_{\mathrm{F}}$ from $X$ to $A$, denoted by $F_{x, A}(t)$ and the probabilistic set-to-set distance mapping $\mathbf{F}: A \times B \rightarrow \Delta_{\mathrm{F}}$ from $A$ to $B$ are, respectively, defined by

$$
\begin{aligned}
& F_{x, A}(t)=\sup \left(F_{x, y}(t): y \in A\right), \quad x \in X, t \in \mathbf{R}, \\
& F_{A, B}(t)=\sup \left(F_{x, y}(t): x \in A, y \in B\right), \quad t \in \mathbf{R} .
\end{aligned}
$$

The Pompeiu-Hausdorff-like probabilistic set-to-set distance is defined by

$$
H_{A, B}(t)=\min \left(\inf _{x \in A} F_{x, B}(t), \inf _{y \in B} F_{y, A}(t)\right) ; \quad \forall t \in \mathbf{R} .
$$

Note that $F_{x, S}(0)=0$ and $F_{S, W}(0)=0$ since $H(0)=0$. If $A, B \in C B(X)$, where $C B(X)$ is the set of all nonempty closed bounded subsets of $X$, then $\sup _{t \in \mathbf{R}} H_{A, B}(t)=\sup _{x \in A} F_{x, B}(t)=$ $\sup _{y \in B} F_{y, A}(t)=1$.

A fuzzy set $A$ in $X$ is a function from $X$ to $[0,1]$ whose grade of membership of $x$ in $A$ is the function-value $A(x)$. The $\alpha$-level set of $A$ is denoted by $[A]_{\alpha}$ defined by

$$
\begin{aligned}
& {[A]_{\alpha}=\{x \in X: A(x) \geq \alpha\} \subseteq X, \text { if } \alpha \in(0,1],} \\
& {[A]_{0}=\overline{\{x \in X: A(x)>0\}} \subseteq X,}
\end{aligned}
$$

where $\bar{B}$ denotes the closure of $B$. Let $\mathrm{F}(X)$ be the collection of all fuzzy sets in a PM-space $(X, \mathbf{F})$. Let $T: X \rightarrow \mathrm{F}(X)$ be a fuzzy mapping from an arbitrary set $X$ to $\mathrm{F}(X)$, which is a fuzzy subset in $X \times X$, and the grade of membership of $y$ in $T(x)$ is $T(x)(y)$. 
For $A, B \in \mathrm{F}(X), A \subset B$ means $A(x) \leq B(x), \forall x \in X$. Note also that if $\alpha \in[\beta, 1]$ and $\beta \in(0,1]$ then $[A]_{\alpha} \subseteq[A]_{\beta}$. If there exists $\alpha \in[0,1]$ such that $[A]_{\alpha},[B]_{\alpha} \in C B(X)$, then define

$$
\begin{aligned}
& H_{[T x]_{\alpha(x)},[T y]_{\alpha(y)}}(t) \\
& \quad=\min \left(\inf _{a \in[T x]} F_{a,[T y]_{\alpha(y)}}(t), \inf _{b \in[T y]} F_{b,[T x]_{\alpha(x)}}(t)\right) ;
\end{aligned}
$$

$\forall t \in \mathbf{R}$

The collection of all the approximate quantities in a metric linear space $X$ is denoted by $W(X) . T: X \rightarrow \mathrm{F}(Y)$ is a fuzzy mapping from an arbitrary set $X$ to $F(Y)$, which is a fuzzy subset in $X \times Y$, and the grade of membership of $y$ in $T(x)$ is $T(x)(y)$.

The notation $f: X \mid Y \rightarrow Z$ means that the domain of the function $f$ from $X$ to $Z$ is restricted to the subset $Y$ of $X$.

The next definition characterizes probabilistic fuzzy fixed points in an appropriate way to establish some results of this paper.

Definition 1. If $\mathrm{F}(X)$ is the collection of all fuzzy sets in the PM-space $(X, \mathbf{F})$, where $X$ is a nonempty abstract set and $T$ : $X \rightarrow \mathrm{F}(X)$ is a fuzzy mapping, then $x \in X$ is a probabilistic $\alpha$-fuzzy fixed point of $T: X \rightarrow \mathrm{F}(X)$ if, for some $\alpha \in(0,1]$, $[T x]_{\alpha} \in C B(X)$ and $x \in[T x]_{\alpha}$; that is, $(T x)(x) \geq \alpha$.

Note that if $X$ is a nonempty abstract set, $(X, \mathbf{F})$ is a PMspace, $A \in \mathrm{F}(X)$, and for some $\alpha \in(0,1],[A]_{\alpha} \in C B(X)$, $T: X \rightarrow \mathrm{F}(X)$ then

(1) $F_{[A]_{\alpha},[A]_{\alpha}}(t)=1 ; \forall t \in \mathbf{R}_{+}$,

(2) if $x \in X$ is a probabilistic $\alpha$-fuzzy fixed point of $T$ : $X \rightarrow \mathrm{F}(X)$ then $F_{x,[T x]_{\alpha}}(t)=1 ; \forall t \in \mathbf{R}_{+}$,

(3) if $[T x]_{\alpha(x)} \in C B(X)$ and $x \in X$ is not a probabilistic $\alpha$-fuzzy fixed point of $T: X \rightarrow \mathrm{F}(X)$ then $x \notin$ $[T x]_{\alpha(x)}$, equivalently, $(T x)(x)<\alpha$, and $F_{x,[T x]_{\alpha}}(t)<$ $1 ; t \in\left[0, t_{1}\right]$ for some $t_{1}=t_{1}(x) \in \mathbf{R}_{+}$.

The following result holds.

Theorem 2. Let $\mathrm{F}(X)$ be the collection of all fuzzy sets in a $P M$-space $(X, \mathbf{F})$, where $X$ is a nonempty abstract set and let $T: X \rightarrow \mathrm{F}(X)$ be a fuzzy mapping. Assume that the following conditions hold:

(1) for each $x \in X$, there exists $\alpha(x) \in(0,1]$ such that $[T x]_{\alpha(x)}$ is a nonempty closed bounded subset of $X$, and each sequence $\left\{x_{n}\right\} \subset X$ of the form $x_{1} \in X$, $x_{n+1} \in\left[T x_{n}\right]_{\alpha\left(x_{n}\right)}$ with $\left[T x_{n}\right]_{\alpha\left(x_{n}\right)} \in C B(X) ; \forall n \in \mathbf{Z}_{0+}$ which satisfies the following contractive constraint for some real constant $k \in(0,1)$ :

$$
\begin{aligned}
H_{[T x]_{\alpha(x)},[T y]_{\alpha(y)}}(k t) \geq & a_{1}(x, y, k t) F_{x,[T x]_{\alpha(x)}}(t) \\
& +a_{2}(x, y, k t) F_{y,[T y]_{\alpha(y)}}(t) \\
& +a_{3}(x, y, k t) F_{x, y}(t) ;
\end{aligned}
$$

$\forall x \in X, \forall y \in[T x]_{\alpha(x)}$, where $a_{i}: X \times X \times \mathbf{R}_{0+} \rightarrow$ $[0,1]$ for $i=1,3 ; a_{2}: X \times X \times \mathbf{R}_{0+} \rightarrow[0,1)$,

(2)

$$
\begin{aligned}
& 0<a(x, y, t)=\sum_{i=1}^{3} a_{i}(x, y, t) \leq 1 \\
& \forall t \in \mathbf{R}_{0+}, \forall x \in X, \forall y \in[T x]_{\alpha(x)} \subset C B(X),
\end{aligned}
$$

(3)

$$
\begin{aligned}
& \lim _{N \rightarrow \infty} \prod_{i=0}^{N}\left[\frac{a_{1}\left(x_{i+1}, x_{i+2}, k^{-i+1} t\right)+a_{3}\left(x_{i+1}, x_{i+2}, k^{-i+1} t\right)}{1-a_{2}\left(x_{i+1}, x_{i+2}, k^{-i+1} t\right)}\right] \\
& \quad=1 ; \quad x_{n+1} \in\left[T x_{n}\right]_{\alpha\left(x_{n}\right)} \in C B(X), \forall t \in \mathbf{R}_{+}, \forall n \in \mathbf{Z}_{0+} .
\end{aligned}
$$

Then, a sequence $\left\{x_{n}\right\}$ may be built for any given arbitrary $x_{1}=$ $x \in X$ satisfying $x_{n+1} \in\left[T x_{n}\right]_{\alpha\left(x_{n}\right)} \in C B(X)$, with $\left\{\alpha\left(x_{n}\right)\right\} \subseteq$ $(0,1]$ satisfying $\lim _{n \rightarrow \infty} F_{x_{n}, x_{n+1}}(t)=1 ; \forall t \in \mathbf{R}_{+}$.

If, in addition, $(X, \mathbf{F})$ is endowed with the minimum triangular norm $\Delta_{M}:[0,1] \times[0,1] \rightarrow[0,1]$ and $\left(X, F, \Delta_{M}\right)$ is a complete Menger space then each of such sequences $\left\{x_{n}\right\}$ is a Cauchy sequence which is convergent to a probabilistic $\alpha^{*}$ fuzzy fixed point $x^{*}$ of $T: X \rightarrow \mathrm{F}(X)$.

Proof. Take arbitrary points $x_{1}=x \in X, x_{2}=y \in\left[T x_{1}\right]_{\alpha\left(x_{1}\right)}$ for some given existing $\alpha\left(x_{1}\right) \in(0,1]$ such that $\left[T x_{1}\right]_{\alpha\left(x_{1}\right)}$ is nonempty and take also some existing $\alpha\left(x_{2}\right) \in(0,1]$ such that $\left[T x_{2}\right]_{\alpha\left(x_{2}\right)}$ is nonempty. Note that since $F_{x, A}(t)=\sup \left(F_{x, y}(t)\right.$ : $y \in A)$, for any $x \in X$ and $t \in \mathbf{R}$; then $F_{x_{1},\left[T x_{1}\right]_{\alpha\left(x_{1}\right)}}(t) \geq$ $F_{x_{1}, x_{2}}(t)$. Thus, one gets from the contractive condition (12) that

$$
\begin{aligned}
& H_{\left[T x_{1}\right]_{\alpha\left(x_{1}\right)},\left[T x_{2}\right]_{\alpha\left(x_{2}\right)}}(k t) \\
& =\min \left(\inf _{a \in\left[T x_{1}\right]_{\alpha\left(x_{1}\right)}} F_{a,\left[T x_{2}\right]_{\alpha\left(x_{2}\right)}}(k t),\right. \\
& \left.\quad \inf _{b \in\left[T x_{2}\right]_{\alpha\left(x_{2}\right)}} F_{b,\left[T x_{1}\right]_{\alpha\left(x_{1}\right)}}(k t)\right) \geq a_{1}\left(x_{1}, x_{2}, k t\right) \\
& \cdot F_{x_{1},\left[T x_{1}\right]_{\alpha(x)}}(t)+a_{2}\left(x_{1}, x_{2}, k t\right) F_{x_{2},\left[T x_{2}\right]_{\alpha\left(x_{2}\right)}}(t) \\
& +a_{3}\left(x_{1}, x_{2}, k t\right) F_{x_{1}, x_{2}}(t) \geq a_{1}\left(x_{1}, x_{2}, k t\right) \\
& \cdot F_{x_{1},\left[T x_{1}\right]_{\alpha\left(x_{1}\right)}}(t)+a_{2}\left(x_{1}, x_{2}, k t\right) F_{x_{2},\left[T x_{2}\right]_{\alpha\left(x_{2}\right)}}(k t) \\
& +a_{3}\left(x_{1}, x_{2}, k t\right) F_{x_{1}, x_{2}}(t)=\left(a_{1}\left(x_{1}, x_{2}, k t\right)\right. \\
& \left.+a_{3}\left(x_{1}, x_{2}, k t\right)\right) F_{x_{1}, x_{2}}(t)+a_{2}\left(x_{1}, x_{2}, k t\right) \\
& \cdot F_{x_{2},\left[T x_{2}\right]_{\alpha\left(x_{2}\right)}}(k t) ; \quad \forall t \in \mathbf{R}_{+}
\end{aligned}
$$

for any given $\alpha\left(x_{2}\right) \in(0,1]$ since $F_{x_{1},\left[T x_{1}\right]_{\alpha\left(x_{1}\right)}}(t) \geq F_{x_{1}, x_{2}}(t)$ for all $t \in \mathbf{R}_{+}$since $x_{2} \in\left[T x_{1}\right]_{\alpha\left(x_{1}\right)}$. Then, again since $x_{2} \in$ $\left[T x_{1}\right]_{\alpha\left(x_{1}\right)}$, the following cases can arise for each $t \in \mathbf{R}_{+}$. 
Case (a). One has

$$
\begin{aligned}
& H_{\left[T x_{1}\right]_{\alpha\left(x_{1}\right)},\left[T x_{2}\right]_{\alpha\left(x_{2}\right)}}(k t)=\inf _{a \in\left[T x_{1}\right]_{\alpha\left(x_{1}\right)}} F_{a,\left[T x_{2}\right]_{\alpha\left(x_{2}\right)}}(k t) \\
& \quad=\min \left(\inf _{b \in\left[T x_{2}\right]_{\alpha\left(x_{2}\right)}} F_{b,\left[T x_{1}\right]_{\alpha\left(x_{1}\right)}}(k t), F_{x_{2},\left[T x_{2}\right]_{\alpha\left(x_{2}\right)}}(k t)\right) \\
& \quad \leq F_{x_{2},\left[T x_{2}\right]_{\alpha\left(x_{2}\right)}}(k t)
\end{aligned}
$$

for some given $t \in \mathbf{R}_{+}$. Thus, from (15) and (16), one gets

$$
\begin{aligned}
F_{x_{2},\left[T x_{2}\right]_{\alpha\left(x_{2}\right)}}(k t) & \\
\geq & \left(a_{1}\left(x_{1}, x_{2}, k t\right)+a_{3}\left(x_{1}, x_{2}, k t\right)\right) F_{x_{1}, x_{2}}(t) \\
& +a_{2}\left(x_{1}, x_{2}, k t\right) F_{x_{2},\left[T x_{2}\right]_{\alpha\left(x_{2}\right)}}(k t) ; \quad \forall t \in \mathbf{R}_{+}
\end{aligned}
$$

and one gets for the given $t \in \mathbf{R}_{+}$that since $H(t)$ is nondecreasing and left-continuous, then

$$
F_{x,[T x]_{\alpha(x)}}(t) \geq F_{x,[T x]_{\alpha(x)}}(k t) ; \quad \forall t \in \mathbf{R}_{+}, \forall x \in X
$$

and since $k \in(0,1)$, one gets from (17) that

$$
\begin{aligned}
& F_{x_{2},\left[T x_{2}\right]_{\alpha\left(x_{2}\right)}}(t) \geq F_{x_{2},\left[T x_{2}\right]_{\alpha\left(x_{2}\right)}}(k t) \\
& \geq\left(a_{1}\left(x_{1}, x_{2}, k t\right)+a_{3}\left(x_{1}, x_{2}, k t\right)\right) F_{x_{1}, x_{2}}(t) \\
& \quad+a_{2}\left(x_{1}, x_{2}, k t\right) F_{x_{2},\left[T x_{2}\right]_{\alpha\left(x_{2}\right)}}(k t)
\end{aligned}
$$

and then since $\left[T x_{2}\right]_{\alpha\left(x_{2}\right)}$ is closed and nonempty, there exists $x_{3} \in\left[T x_{2}\right]_{\alpha\left(x_{2}\right)}$ such that from (19) and the fact that $F_{x_{2},\left[T x_{2}\right]_{\alpha\left(x_{2}\right)}}(t) \geq F_{x_{2},\left[T x_{2}\right]_{\alpha\left(x_{2}\right)}}(k t) ; \forall t \in \mathbf{R}_{+}$,

$$
\begin{aligned}
F_{x_{2}, x_{3}}(t) & \geq F_{x_{2}, x_{3}}(k t)=F_{x_{2},\left[T x_{2}\right]_{\alpha\left(x_{2}\right)}}(k t) \\
& \geq \frac{a_{1}\left(x_{1}, x_{2}, k t\right)+a_{3}\left(x_{1}, x_{2}, k t\right)}{1-a_{2}\left(x_{1}, x_{2}, k t\right)} F_{x_{1}, x_{2}}(t) ;
\end{aligned}
$$

\section{$\forall t \in \mathbf{R}_{+}$}

and, equivalently,

$$
F_{x_{2}, x_{3}}(t) \geq g\left(x_{1}, x_{2}, t\right) F_{x_{1}, x_{2}}\left(k^{-1} t\right) ; \quad \forall t \in \mathbf{R}_{+},
$$

where $g\left(x_{1}, x_{2}, t\right)=\left(a_{1}\left(x_{1}, x_{2}, t\right)+a_{3}\left(x_{1}, x_{2}, t\right)\right) /\left(1-a_{2}\left(x_{1}\right.\right.$, $\left.\left.x_{2}, t\right)\right) ; \forall t \in \mathbf{R}_{+}$.

Case (b). One has

$$
\begin{aligned}
& H_{\left[T x_{1}\right]_{\alpha\left(x_{1}\right)},\left[T x_{2}\right]_{\alpha\left(x_{2}\right)}}(k t)=\inf _{b \in\left[T x_{2}\right]_{\alpha\left(x_{2}\right)}} F_{b,\left[T x_{1}\right]_{\alpha\left(x_{1}\right)}}(k t) \\
& \quad=\min \left(\inf _{a \in\left[T x_{1}\right]_{\alpha\left(x_{1}\right)}} F_{a,\left[T x_{2}\right]_{\alpha\left(x_{2}\right)}}(k t), F_{x_{1},\left[T x_{1}\right]_{\alpha\left(x_{1}\right)}}(k t)\right) \\
& \quad \leq F_{x_{1},\left[T x_{1}\right]_{\alpha\left(x_{1}\right)}}(k t)
\end{aligned}
$$

and some $t \in \mathbf{R}_{+}$and $x_{3} \in\left[T x_{2}\right]_{\alpha\left(x_{2}\right)}$ can be chosen for the previously taken $x_{2} \in\left[T x_{1}\right]_{\alpha\left(x_{1}\right)}$ so that $F_{x_{2}, x_{3}}(k t)=$ $\inf _{a \in\left[T x_{1}\right]_{\alpha\left(x_{1}\right)}} F_{a,\left[T x_{2}\right]_{\alpha\left(x_{2}\right)}}(k t)$. Thus,

$$
\begin{aligned}
& H_{\left[T x_{1}\right]_{\alpha\left(x_{1}\right)},\left[T x_{2}\right]_{\alpha\left(x_{2}\right)}}(k t)=\inf _{b \in\left[T x_{2}\right]_{\alpha\left(x_{2}\right)}} F_{b,\left[T x_{1}\right]_{\alpha\left(x_{1}\right)}} \\
& \quad=F_{x_{2}, x_{3}}(k t)
\end{aligned}
$$

and since $F_{x_{2},\left[T x_{2}\right]_{\alpha\left(x_{2}\right)}}(k t) \geq F_{x_{2}, x_{3}}(k t)$, one gets for the given $t \in \mathbf{R}_{+}$

$$
\begin{aligned}
F_{x_{2}, x_{3}}(t) \geq & F_{x_{2}, x_{3}}(k t) \\
\geq & a_{1}\left(x_{1}, x_{2}, t\right) F_{x_{1},\left[T x_{1}\right]_{\alpha\left(x_{1}\right)}}(t) \\
& +a_{3}\left(x_{1}, x_{2}, t\right) F_{x_{1}, x_{2}}(t) \\
& +a_{2}\left(x_{1}, x_{2}, t\right) F_{x_{2},\left[T x_{2}\right]_{\alpha\left(x_{2}\right)}}(k t) \\
\geq & \left(a_{1}\left(x_{1}, x_{2}, t\right)+a_{3}\left(x_{1}, x_{2}, t\right)\right) F_{x_{1}, x_{2}}(t) \\
& +a_{2}\left(x_{1}, x_{2}, t\right) F_{x_{2}, x_{3}}(k t) .
\end{aligned}
$$

Then, one gets from (24) that

$$
\begin{aligned}
& \left(1-a_{2}\left(x_{1}, x_{2}, t\right)\right) F_{x_{2}, x_{3}}(k t) \\
& \quad \geq\left(a_{1}\left(x_{1}, x_{2}, t\right)+a_{3}\left(x_{1}, x_{2}, t\right)\right) F_{x_{1}, x_{2}}(t)
\end{aligned}
$$

which implies (21). So, from Cases (a)-(b), for each given $t \in \mathbf{R}_{+}$, and $x_{1} \in X$, there exist $\alpha\left(x_{1}\right), \alpha\left(x_{2}\right) \in(0,1]$ and points $x_{2} \in\left[T x_{1}\right]_{\alpha\left(x_{1}\right)}$ and $x_{2} \in\left[T x_{2}\right]_{\alpha\left(x_{2}\right)}$ in nonempty level sets $\left[T x_{1}\right]_{\alpha\left(x_{1}\right)}$ and $\left[T x_{2}\right]_{\alpha\left(x_{2}\right)}$ such that (22) holds. Proceeding recursively, one gets that a sequence $\left\{x_{n}\right\}$ may be built for any arbitrary $x_{1}=x \in X$ and $x_{n+1} \in\left[T x_{n}\right]_{\alpha\left(x_{n}\right)} \in C B(X)$ with $\left\{\alpha\left(x_{n}\right)\right\} \subseteq(0,1] ; \forall n \in \mathbf{Z}_{+}$which satisfies the recursion

$$
\begin{aligned}
& F_{x_{2}, x_{3}}(t) \geq g\left(x_{1}, x_{2}, t\right) F_{x_{1}, x_{2}}\left(k^{-1} t\right) ; \quad \forall t \in \mathbf{R}_{+}, \\
& F_{x_{3}, x_{4}}(t) \geq g\left(x_{2}, x_{3}, t\right) F_{x_{2}, x_{3}}\left(k^{-1} t\right) \\
& \geq g\left(x_{2}, x_{3}, t\right) g\left(x_{1}, x_{2}, k^{-1} t\right) F_{x_{1}, x_{2}}\left(k^{-2} t\right) ; \\
& \forall t \in \mathbf{R}_{+},
\end{aligned}
$$

$$
F_{x_{n+1}, x_{n+2}}(t) \geq\left[\prod_{i=1}^{n} g\left(x_{i}, x_{i+1}, k^{-i+1} t\right)\right] F_{x_{1}, x_{2}}\left(k^{-n} t\right)
$$

$\forall t \in \mathbf{R}_{+}, \forall n \in \mathbf{Z}_{+}$,

where

$$
\begin{aligned}
0 & <g\left(x_{i}, x_{i+1}, t\right)=\frac{a_{1}\left(x_{i}, x_{i+1}, t\right)+a_{3}\left(x_{i}, x_{i+1}, t\right)}{1-a_{2}\left(x_{i}, x_{i+1}, t\right)} \\
& \leq 1 ; \quad \forall t \in \mathbf{R}_{+}, \forall i \in \mathbf{Z}_{+} .
\end{aligned}
$$

Note that since

$$
\begin{aligned}
& 0<a\left(x_{i}, x_{i+1}, t\right) \leq 1, \\
& 0 \leq a_{2}\left(x_{i}, x_{i+1}, t\right)<1 ;
\end{aligned}
$$

$\forall t \in \mathbf{R}_{+}, \forall i \in \mathbf{Z}_{+}$,

$\prod_{i=0}^{n}\left[\frac{a_{1}\left(x_{i}, x_{i+1}, k^{-i+1} t\right)+a_{3}\left(x_{i}, x_{i+1}, k^{-i+1} t\right)}{1-a_{2}\left(x_{i}, x_{i+1}, k^{-i+1} t\right)}\right]$ 
then $\delta\left(\Gamma_{1 t}\right) / \delta\left(\Gamma_{0 t}\right)=+\infty ; \forall t \in \mathbf{R}_{+}, \forall i \in \mathbf{Z}_{+}$, where $\delta\left(\Gamma_{0 t}\right)=$ $\prod_{j=0}^{\infty}\left[\delta_{j t}^{0}\right]=\prod_{j=0}^{\infty}\left[1-\delta_{j t}^{1}\right]$ and $\delta\left(\Gamma_{1 t}\right)=\prod_{j=0}^{\infty}\left[\delta_{j t}^{1}\right]=\prod_{j=0}^{\infty}[1-$ $\left.\delta_{j t}^{0}\right] ; \forall t \in \mathbf{R}_{+}$are discrete measures of the subsequent sets

$$
\begin{aligned}
\Gamma_{0 t} & =\Gamma_{0 t}\left(\left\{x_{j}\right\}\right) \\
& =\left\{j=j(t) \in \mathbf{Z}_{0+}: g\left(x_{j}, x_{j+1}, t\right) \in[0,1)\right\} ; \\
\qquad t \in \mathbf{R}_{+}, & \\
\Gamma_{1 t} & =\Gamma_{1 t}\left(\left\{x_{j}\right\}\right) \\
& =\left\{j=j(t) \in \mathbf{Z}_{0+}: g\left(x_{j}, x_{j+1}, t\right)=1\right\} ;
\end{aligned}
$$$$
\forall t \in \mathbf{R}_{+} \text {, }
$$

where $\delta_{j t}^{0}$ and $\delta_{j t}^{1}$ are Dirac measures defined by

$$
\begin{aligned}
& \delta_{j t}^{0}=1-\delta_{j t}^{1}=\left\{\begin{array}{ll}
1, & \text { if } j \in \Gamma_{0 t}, \\
0, & \text { if } j \notin \Gamma_{0 t} ;
\end{array} \quad \forall t \in \mathbf{R}_{+},\right. \\
& \delta_{j t}^{1}=1-\delta_{j t}^{0}=\left\{\begin{array}{ll}
1, & \text { if } j \in \Gamma_{1 t}, \\
0, & \text { if } j \notin \Gamma_{1 t} ;
\end{array} \quad \forall t \in \mathbf{R}_{+} .\right.
\end{aligned}
$$

Then, one gets from (26), (29), and $\lim _{n \rightarrow \infty} F_{x_{1}, x_{2}}\left(k^{-n} t\right)=$ $\lim _{\tau \rightarrow+\infty}-H(\tau)=H\left(+\infty^{-}\right)=1 ; \forall t \in \mathbf{R}_{+}$, since $k \in(0,1)$, that $\lim _{n \rightarrow \infty} F_{x_{n+1}, x_{n}}(t)=1 ; \forall t \in \mathbf{R}_{+}$with $x_{n+1} \in\left[T x_{n}\right]_{\alpha\left(x_{n}\right)}$; $\forall n \in \mathbf{Z}_{+}$since

$$
\begin{aligned}
& \lim _{n \rightarrow \infty} F_{x_{n+1}, x_{n+2}}(t) \geq\left(\lim _{n \rightarrow \infty}\left[\prod_{i=1}^{n} g\left(x_{i}, x_{i+1}, k^{-i+1} t\right)\right]\right) \\
& \cdot\left(\lim _{n \rightarrow \infty} F_{x_{1}, x_{2}}\left(k^{-n} t\right)\right) ; \quad \forall t \in \mathbf{R}_{+} .
\end{aligned}
$$

Since $\lim _{n \rightarrow \infty} F_{x_{n+1}, x_{n}}(t)=\lim _{n \rightarrow \infty} F_{x_{1}, x_{2}}\left(k^{-n} t\right)=1 ; \forall t \epsilon$ $\mathbf{R}_{+}$and any given $x_{1} \in X$ then for any given $\varepsilon \in \mathbf{R}_{+}$ and $\lambda \in(0,1)$, there is $N=N(\varepsilon, \lambda) \in \mathbf{Z}_{0+}$ such that $F_{x_{n+1}, x_{n}}(\varepsilon)>1-\lambda ; \forall n(\geq N) \in \mathbf{Z}_{0+}$. Assume on the contrary that there exist $n_{k} \geq N, n_{k+2}>n_{k+1}>n_{k}$ such that $F_{x_{n_{k+i+1}}, x_{n_{k+i}}}(\varepsilon) \geq F_{x_{n_{k+i+1}}, x_{n_{k+i}}}(\varepsilon / 2)>1-\lambda$ for $i=0,1$ and $1-\lambda \geq F_{x_{n_{k+2}}, x_{n_{k}}}(\varepsilon)$. Then, one has the following contradiction for the subsequence $\left\{x_{n_{k}}\right\}$ of $\left\{x_{n}\right\}$ :

$$
\begin{aligned}
1-\lambda & \geq F_{x_{n_{k+2}}, x_{n_{k}}}(\varepsilon) \\
& \geq \Delta_{M}\left(F_{x_{n_{k+2}}, x_{n_{k+1}}}\left(\frac{\varepsilon}{2}\right), F_{x_{n_{k+1}}, x_{n_{k}}}\left(\frac{\varepsilon}{2}\right)\right) \\
& >1-\lambda .
\end{aligned}
$$

Then, $F_{x_{n+1}, x_{n}}(\varepsilon)>1-\lambda ; \forall n(\geq N) \in \mathbf{Z}_{0+}$ so that $\left\{x_{n}\right\}$ is a Cauchy sequence. Since $\left(X, \mathbf{F}, \Delta_{M}\right)$ is complete, one gets $\left\{x_{n}\right\} \rightarrow x^{*}$ and $\left\{\alpha\left(x_{n}\right)\right\} \rightarrow \alpha\left(x^{*}\right)$.
It is now proved that $x^{*} \in\left[T x^{*}\right]_{\alpha\left(x^{*}\right)}$. Assume on the contrary that $x^{*} \notin\left[T x^{*}\right]_{\alpha\left(x^{*}\right)}$; that is, $\left(T x^{*}\right)\left(x^{*}\right)<\alpha\left(x^{*}\right)$ and, for some given $y \in\left[T x^{*}\right]_{\alpha\left(x^{*}\right)}$, there is $t_{1}=t_{1}(y) \in \mathbf{R}_{+}$ such that $F_{x^{*},\left[T x^{*}\right]_{\alpha\left(x^{*}\right)}}(t)<1$ for $t \in\left[0, t_{1}\right]$. Then, since $x_{n+1} \in\left[T x_{n}\right]_{\alpha\left(x_{n}\right)} ; \forall n \in \mathbf{Z}_{+}$and since $y \neq x^{*}$,

$$
1>F_{x^{*},\left[T x^{*}\right]_{\alpha\left(x^{*}\right)}}(t)=F_{x^{*}, y}(t) \geq \Delta_{M}\left(F_{x^{*}, x_{n}}\left(\frac{t}{2}\right),\right.
$$

$$
\begin{aligned}
& \left.\Delta_{M}\left(F_{x_{n}, x_{n+1}}\left(\frac{t}{4}\right), F_{x_{n+1}, y}\left(\frac{t}{4}\right)\right)\right) \\
& =\Delta_{M}\left(F_{x^{*}, x_{n}}\left(\frac{t}{2}\right),\right.
\end{aligned}
$$

$$
\left.\Delta_{M}\left(F_{x_{n},\left[T x_{n}\right]_{\alpha\left(x_{n}\right)}}\left(\frac{t}{4}\right), F_{\left[T x_{n}\right]_{\alpha\left(x_{n}\right), y}}\left(\frac{t}{4}\right)\right)\right)
$$

$$
t \in\left[0, t_{1}\right] .
$$

If $y \in\left[T x^{*}\right]_{\alpha\left(x^{*}\right)}$ is chosen to fulfill $F_{\left[T x_{n}\right]_{\alpha\left(x_{n}\right), y}}\left(t_{1} / 4\right)=$ $F_{\left[T x_{n}\right]_{\alpha\left(x_{n}\right)},\left[T x^{*}\right]_{\alpha\left(x^{*}\right)}}\left(t_{1} / 4\right)$, then

$$
\begin{aligned}
& 1>\limsup _{n \rightarrow \infty} \Delta_{M}\left(F_{x^{*}, x_{n}}\left(\frac{t_{1}}{2}\right), \Delta_{M}\left(F_{x_{n},\left[T x_{n}\right]_{\alpha\left(x_{n}\right)}}\left(\frac{t_{1}}{4}\right),\right.\right. \\
& \left.\left.F_{\left[T x_{n}\right]_{\alpha\left(x_{n}\right)}, y}\left(\frac{t_{1}}{4}\right)\right)\right) \geq \Delta_{M}\left(\lim _{n \rightarrow \infty} F_{x^{*}, x_{n}}\left(\frac{t_{1}}{2}\right),\right. \\
& \Delta_{M}\left(\lim _{n \rightarrow \infty} F_{x_{n},\left[T x_{n}\right]_{\alpha\left(x_{n}\right)}}\left(\frac{t_{1}}{4}\right),\right. \\
& \left.\left.\left.\quad \limsup _{n \rightarrow \infty} F_{\left[T x_{n}\right]_{\alpha\left(x_{n}\right)},\left[T x^{*}\right]_{\alpha\left(x^{*}\right)}}\left(\frac{t_{1}}{4}\right)\right)\right)=\Delta_{M}\left(1, \limsup _{n \rightarrow \infty} F_{\left.\left[T x_{n}\right]_{\alpha\left(x_{n}\right)}\right),\left[T x^{*}\right]_{\alpha\left(x^{*}\right)}}\left(\frac{t_{1}}{4}\right)\right)\right) \\
& \quad=\limsup _{n \rightarrow \infty} F_{\left.\left[T x_{n}\right]_{\alpha\left(x_{n}\right)}\right)\left[T x^{*}\right]_{\alpha\left(x^{*}\right)}}\left(\frac{t_{1}}{4}\right) \\
& \quad=\lim _{n \rightarrow \infty} F_{\left[T x^{*}\right]_{\alpha\left(x^{*}\right)},\left[T x^{*}\right]_{\alpha\left(x^{*}\right)}}\left(\frac{t_{1}}{4}\right)=1,
\end{aligned}
$$

for some $t_{1} \in \mathbf{R}_{+}$,

a contradiction. Then, $x^{*} \in\left[T x^{*}\right]_{\alpha\left(x^{*}\right)}$ with $\alpha^{*}=\alpha\left(x^{*}\right)$; that is, it is a probabilistic $\alpha^{*}$-fuzzy fixed point of $T: X \rightarrow \mathrm{F}(X)$.

Corollary 3. Let $\mathrm{F}(X)$ be the collection of all fuzzy sets in a PM-space $(X, \mathbf{F})$, where $X$ is a nonempty abstract set, and let $T: X \rightarrow F(X)$ be a fuzzy mapping. Assume that the contractive condition (12) holds for some real constant $k \epsilon$ $(0,1)$ subject to condition (2) of Theorem 2 and the specific particular form of condition (3): 
$\left(3^{\prime}\right)$ there exists and strictly increasing sequence of nonnegative integers $\left\{N_{n}\right\}$ which satisfies

$$
\prod_{j=N_{n+1}}^{N_{n+2}-1}\left[\frac{a_{2}\left(x, y, k^{-i+1} t\right)+a_{3}\left(x, y, k^{-i+1} t\right)}{1-a_{2}\left(x, y, k^{-i+1} t\right)}\right]=\frac{1}{\prod_{j=N_{n}}^{N_{n+1}-1}\left[\left(a_{2}\left(x, y, k^{-i+1} t\right)+a_{3}\left(x, y, k^{-i+1} t\right)\right) /\left(1-a_{2}\left(x, y, k^{-i+1} t\right)\right)\right]}
$$

$$
\forall t \in \mathbf{R}_{+}, \forall x \in X, y \in[T x]_{\alpha(x)} \subset C B(X), \forall n \in \mathbf{Z}_{0+} .
$$

Proof. It is direct from that of Theorem 2 since condition $\left(3^{\prime}\right)$ guarantees condition (3) of Theorem 2 for any finite first element $N_{0} \in \mathbf{Z}_{0+}$ of a strictly increasing sequence $\left\{N_{n}\right\}$ subject to $0<M_{1} \leq N_{n+1}-N_{n} \leq M_{2}<+\infty$.

Corollary 4. Theorem 2 and Corollary 3 also hold if the contractive condition (1) is modified as follows:

$$
\begin{aligned}
H_{\left[T x_{1}\right]_{\alpha\left(x_{1}\right)},\left[T x_{2}\right]_{\alpha\left(x_{2}\right)}}(k t) & \\
\geq & a_{1}\left(x_{1}, x_{2}, k t\right) F_{x_{1},\left[T x_{1}\right]_{\alpha\left(x_{1}\right)}}(t) \\
& +a_{2}\left(x_{1}, x_{2}, k t\right) F_{x_{2},\left[T x_{2}\right]_{\alpha\left(x_{2}\right)}}(k t)+a_{3}\left(x_{1}, x_{2}, k t\right) F_{x_{1}, x_{2}}(t) \\
= & \left(a_{1}\left(x_{1}, x_{2}, k t\right)+a_{3}\left(x_{1}, x_{2}, k t\right)\right) F_{x_{1}, x_{2}}(t) \\
& +a_{2}\left(x_{1}, x_{2}, k t\right) F_{x_{2},\left[T x_{2}\right]_{\alpha\left(x_{2}\right)}}(k t) ; \\
\forall t \in & \mathbf{R}_{+}, \forall x_{1}=x \in X, x_{n+1} \in\left[T x_{n}\right]_{\alpha\left(x_{n}\right)} \subset C B(X), \forall n \in \mathbf{Z}_{0+} .
\end{aligned}
$$

Proof. It is direct from that of Theorem 2 since the above contraction condition follows from (12) as a lower-bound which has been used in the proof of Theorem 2 .

Corollary 5. Let $\mathrm{F}(X)$ be the collection of all fuzzy sets in a PM-space $(X, \mathbf{F})$, where $X$ is a nonempty abstract set, and let $T: X \rightarrow \mathrm{F}(X)$ be a fuzzy mapping. Assume that the following conditions are fulfilled:

(1) for each $x \in X$, there exists $\alpha(x) \in(0,1]$ such that $[T x]_{\alpha(x)}$ is a nonempty closed bounded subset of $X$, and each sequence $\left\{x_{n}\right\} \subset X$ of the form $x_{1} \in X, x_{n+1} \in$ $\left[T x_{n}\right]_{\alpha\left(x_{n}\right)} \in C B(X) ; \forall n \in \mathbf{Z}_{0+}$ which satisfies for some real constant $k \in(0,1)$ the contractive constraint:

$$
\begin{aligned}
& H_{[T x]_{\alpha(x)},[T y]_{\alpha(y)}}(k t) \geq \min \left(1, a_{1}(x, y, k t) F_{x,[T x]_{\alpha(x)}}(t)\right. \\
& \left.+a_{2}(x, y, k t) F_{y,[T y]_{\alpha(y)}}(t)+a_{3}(x, y, k t) F_{x, y}(t)\right)
\end{aligned}
$$

$\forall x \in X, \forall y \in[T x]_{\alpha(x)}$, where $a_{i}: X \times X \times \mathbf{R}_{0+} \rightarrow[0,1]$ for $i=1,3 ; a_{2}: X \times X \times \mathbf{R}_{0+} \rightarrow[0,1)$.

Then, a sequence $\left\{x_{n}\right\}$ may be built for any given arbitrary $x_{1}=x \in X$ satisfying $x_{n+1} \in\left[T x_{n}\right]_{\alpha\left(x_{n}\right)} \in C B(X)$, with $\left\{\alpha\left(x_{n}\right)\right\} \subseteq(0,1]$ and $\lim _{n \rightarrow \infty} F_{x_{n}, x_{n+1}}(t)=1 ; \forall t \in \mathbf{R}_{+}$.

If, in addition, $(X, \mathbf{F})$ is endowed with the minimum triangular norm $\Delta_{M}:[0,1] \times[0,1] \rightarrow[0,1]$ and $\left(X, F, \Delta_{M}\right)$ is a complete Menger space then each above sequence $\left\{x_{n}\right\}$ is a Cauchy sequence which is convergent to a probabilistic $\alpha^{*}$ fuzzy fixed point $x^{*}$ of $T: X \rightarrow \mathrm{F}(X)$.
Proof. Define the indicator function sequence $\sigma_{i}: X \times X \times$ $\mathbf{R}_{0+} \rightarrow\{0,1\} ; i \in \mathbf{Z}_{+}$as

$$
\begin{aligned}
& \sigma_{i}\left(x_{i}, x_{i+1}, k^{-i+1} t\right) \\
& \quad= \begin{cases}1, & \text { if } g\left(x_{i}, x_{i+1}, k^{-i+1} t\right) F_{x_{i}, x_{i+1}}\left(k^{-i} t\right) \leq 1, \\
0, & \text { otherwise, }\end{cases}
\end{aligned}
$$

$\forall t \in \mathbf{R}_{+}$

with $g\left(x_{i}, x_{i+1}, t\right)$ defined as in Theorem 2 . Then, even if for some $j \in \mathbf{Z}_{+}$and all $i(\geq j) \in \mathbf{Z}_{+}, \sigma_{i}\left(x_{i}, x_{i+1}, t\right)=0$ because $g\left(x_{i}, x_{i+1}, k^{-i+1} t\right) F_{x_{i}, x_{i+1}}\left(k^{-i} t\right)>1 ; \forall i(\geq j) \in \mathbf{Z}_{+}$, it follows from (38)-(39) and (26) that $\lim _{n \rightarrow \infty} F_{x_{n+1}, x_{n}}(t)=1 ; \forall t \in \mathbf{R}_{+}$ with $x_{n+1} \in\left[T x_{n}\right]_{\alpha\left(x_{n}\right)} ; \forall n \in \mathbf{Z}_{+}$. The rest of the proof is close to that of Theorem 2 .

Example 6. It is claimed through this example to revisit the idea of fuzzy fixed point addressed in $[4-6,32]$ to that of probabilistic fuzzy fixed point according to the definition and the formalism given above. Consider $X=$ $\{0.6,0.7,0.8\},\{0.6\},\{0.7\},\{0.8\}$ and let $T: X \rightarrow \mathrm{F}(X)$ be a probabilistic fuzzy mapping defined as follows:

$$
T(0.6)(t)=T(0.8)(t)= \begin{cases}\frac{3}{4}, & \text { if } t=0.8, \\ \frac{1}{2}, & \text { if } t=0.7, \\ 0, & \text { if } t=0.6 ;\end{cases}
$$

$$
T(0.7)(t)= \begin{cases}0, & \text { if } t=0.8 \\ \frac{1}{3}, & \text { if } t=0.7 \\ \frac{3}{4}, & \text { if } t=0.6 .\end{cases}
$$

The $\alpha$-level sets are

$$
\begin{aligned}
& {[T 0.6]_{1 / 2}=[T 0.8]_{1 / 2}=\{0.7,0.8\},} \\
& {[T 0.6]_{3 / 4}=[T 0.8]_{3 / 4}=\{0.8\},} \\
& {[T 0.7]_{3 / 4}=\{0.6\} ;} \\
& {[T 0.7]_{1 / 3}=\{0.7\} .}
\end{aligned}
$$


Note that $F_{x,[T x]_{\alpha(x)}}(t)=\sup \left(F_{x, y}(t): y \in[T x]_{\alpha(x)}\right)$, for any $x \in X$ and $t \in \mathbf{R}$ and some $\alpha(x) \in(0,1]$. The probability density functions are as follows with $F_{x, y}(t)=t /(t+|x-y|)$; $\forall x, y \in X, \forall t \in \mathbf{R}_{+}$:

$$
\begin{aligned}
F_{0.6,[T 0.6]_{3 / 4}}(t) & =F_{0.6,0.8}(t)=\frac{t}{t+0.2} ; \quad \forall t \in \mathbf{R}_{+}, \\
F_{0.6,[T 0.6]_{1 / 2}}(t) & =F_{0.6,0.7}(t)=\frac{t}{t+0.1} ; \quad \forall t \in \mathbf{R}_{+}, \\
F_{0.8,[T 0.8]_{1 / 2}}(t) & =F_{0.8,0.7}(t)=\frac{t}{t+0.1} ; \quad \forall t \in \mathbf{R}_{+}, \\
F_{0.8,[T 0.8]_{3 / 4}}(t) & =F_{0.8,0.8}(t)=1 ; \quad \forall t \in \mathbf{R}_{+}, \\
F_{0.7,[T 0.7]_{3 / 4}}(t) & =F_{0.7,0.6}(t)=\frac{t}{t+0.1} ; \quad \forall t \in \mathbf{R}_{+}, \\
F_{0.7,[T 0.7]_{1 / 3}}(t) & =F_{0.7,0.7}(t)=1 ; \quad \forall t \in \mathbf{R}_{+}, \\
H_{[T x]_{1 / 2},[T x]_{1 / 2}}(t) & =\frac{t}{t+0.1}, \\
H_{[T x]_{3 / 4},[T x]_{3 / 4}}(t) & =1, \quad \text { for } x=0.6,0.8 ; \forall t \in \mathbf{R}_{+}, \\
H_{[T x]_{1 / 2},[T y]_{3 / 4}}(t) & =\frac{t}{t+0.1}, \\
H_{[T 0.7]_{1 / 3},[T 0.7]_{1 / 3}}(t) & =1 ; \quad \forall t \in \mathbf{R}_{+}, \\
H_{[T 0.7]_{3 / 4},[T 0.7]_{3 / 4}}(t) & =\frac{t}{t+0.1} ; \quad \forall t \in \mathbf{R}_{+}, \quad \text { for } x=0.6,0.8 ; \forall t \in \mathbf{R}_{+}, \\
H_{[T x]_{1 / 2},[T 0.7]_{3 / 4}}(t) & =\frac{t}{t+0.2}, \\
H_{[T x]_{1 / 2},[T 0.7]_{1 / 3}}(t) & =\frac{t}{t+0.1}, \\
\text { for } x, y=0.6,0.8 ; \forall t \in \mathbf{R}_{+}, &
\end{aligned}
$$

Assume that the contractive condition of Theorem 2 holds under the form

$$
\begin{aligned}
& H_{[T x]_{\alpha(x)},[T y]_{\alpha(y)}}(t) \geq \alpha\left(x_{n}, x_{n+1}, t, n\right) \\
& \quad \cdot\left[F_{x_{n},\left[T x_{n}\right]_{\alpha\left(x_{n}\right)}}\left(k^{-1} t\right)+F_{x_{n+1},\left[T x_{n+1}\right]_{\alpha\left(x_{n+1}\right)}}\left(k^{-1} t\right)\right. \\
& \left.\quad+F_{x_{n}, x_{n+1}}\left(k^{-1} t\right)\right] ; \quad n \in \mathbf{Z}_{0+}
\end{aligned}
$$

for sequences $\left\{x_{n}\right\} \subset X$ with initial points $x_{0}=x \in X, x_{1} \in$ $\left[T x_{0}\right]_{\alpha}$, where $\alpha(x, y, t, n)=\alpha_{i}(x, y, t, n) ; i=1,2,3, \forall t \in \mathbf{R}_{+}$ satisfies

$$
\begin{aligned}
& \alpha(x, y, t, n)=\alpha_{a}(t) \leq \frac{k t}{3(k t+0.2)} \\
& i=1,2,3, \forall t \in \mathbf{R}_{+}, \forall n(\leq \ell) \in \mathbf{Z}_{0+}, \\
& \alpha(x, y, t, n)=\alpha_{b}(t) \leq \frac{1}{3}\left(1-e^{-\lambda t}\right) ; \\
& i=1,2,3, \forall t \in \mathbf{R}_{+}, \forall n(\leq \ell) \in \mathbf{Z}_{0+},
\end{aligned}
$$

for some $\ell(\geq 2) \in \mathbf{Z}_{0+}$, some $k \in(0,1)$, and some $\lambda \in \mathbf{R}_{+}$. Note that $[T 0.7]_{1 / 3}=\{0.7\}$ with $F_{0.7,[T 0.7]_{1 / 3}}(t)=F_{0.7,0.7}(t)=$ $1 ; \forall t \in \mathbf{R}_{+}$is a probabilistic 1/3-fuzzy fixed point of $T$ : $X \rightarrow \mathrm{F}(X)$ to which the sequences $\{0.6,0.8,0.7,0.7, \ldots\}$, $\{0.8,0.6,0.7,0.7, \ldots\}$ converge.

\section{Further Results}

Note that the uniqueness of probabilistic fuzzy fixed points is not an interesting property to study in the context of probabilistic fuzzy fixed point since distinct level sets associated with mappings of the form $T: X \rightarrow \mathrm{F}(X)$ can easily have intersections of cardinal greater than one in many problems in the fuzzy context. The subsequent result gives conditions for the case when several distinct probabilistic fuzzy fixed points, if they exist, are in the intersections of their respective level sets under slightly extended contractive conditions of those given in Section 2. The extended conditions are of direct applicability.

Theorem 7. Consider a complete probabilistic metric space $\left(X, \mathrm{~F}, \Delta_{M}\right)$ under all the assumptions of Theorem 2 with an extended contractive condition (12) such that it also holds for any $x, y \in X$ being probabilistic $\alpha\left(x^{*}\right)$-fuzzy fixed points $x=x^{*} \in\left[T x^{*}\right]_{\alpha\left(x^{*}\right)}$ and $y=y^{*} \in\left[T y^{*}\right]_{\alpha\left(y^{*}\right)}$ of $T: X \rightarrow$ $\mathrm{F}(X)$. Then, the set $\left[T y^{*}\right]_{\alpha\left(y^{*}\right)} \cap\left[T x^{*}\right]_{\alpha\left(x^{*}\right)}$ is nonempty and $x^{*}, y^{*} \in\left(\left[T y^{*}\right]_{\alpha\left(y^{*}\right)} \cap\left[T x^{*}\right]_{\alpha\left(x^{*}\right)}\right)$.

Proof. If $x^{*}=y^{*}$ the result is obvious. Assume that there exist a probabilistic $\alpha\left(x^{*}\right)$-fuzzy fixed point $x^{*} \in\left[T x^{*}\right]_{\alpha\left(x^{*}\right)}$ and a probabilistic $\alpha\left(y^{*}\right)$-fuzzy fixed point $y^{*}\left(\neq x^{*}\right) \in\left[T y^{*}\right]_{\alpha\left(y^{*}\right)}$. Consider two convergent sequences $\left\{x_{n}\right\} \rightarrow x^{*}$ and $\left\{y_{n}\right\} \rightarrow$ $y^{*}$ in $X$. Then,

$$
\begin{aligned}
& F_{x_{n}, y_{n}}(t) \geq \Delta_{M}\left(F_{x^{*}, x_{n}}\left(\frac{t}{2}\right), \Delta_{M}\left(F_{x^{*}, y^{*}}\left(\frac{t}{4}\right),\right.\right. \\
& \left.\left.F_{y_{n}, y^{*}}\left(\frac{t}{4}\right)\right)\right) ; \quad \forall t \in \mathbf{R}_{+}, \\
& \liminf _{n \rightarrow \infty} F_{x_{n}, y_{n}}(t) \geq \liminf _{n \rightarrow \infty} \Delta_{M}\left(F_{x^{*}, x_{n}}\left(\frac{t}{2}\right),\right. \\
& \left.\Delta_{M}\left(F_{x^{*}, y^{*}}\left(\frac{t}{4}\right), F_{y_{n}, y^{*}}\left(\frac{t}{4}\right)\right)\right) \\
& \geq \Delta_{M}\left(\lim _{n \rightarrow \infty} F_{x^{*}, x_{n}}\left(\frac{t}{2}\right), \Delta_{M}\left(F_{x^{*}, y^{*}}\left(\frac{t}{4}\right),\right.\right. \\
& \left.\left.\lim _{n \rightarrow \infty} F_{y_{n}, y^{*}}\left(\frac{t}{4}\right)\right)\right)=\Delta_{M}\left(1, \Delta_{M}\left(F_{x^{*}, y^{*}}\left(\frac{t}{4}\right), 1\right)\right) \\
& \geq F_{x^{*}, y^{*}}\left(\frac{t}{4}\right) ; \quad \forall t \in \mathbf{R}_{+} .
\end{aligned}
$$

Assume that $F_{y^{*},\left[T x^{*}\right]_{\alpha\left(x^{*}\right)}}(k t) \geq F_{x^{*},\left[T y^{*}\right]_{\alpha\left(y^{*}\right)}}(k t) ; \forall t \in \mathbf{R}_{+}$. Then, from the extended contractive condition (12) and since $1=F_{x^{*},\left[T x^{*}\right]_{\alpha\left(x^{*}\right)}}(t)=F_{y^{*},\left[T y^{*}\right]_{\alpha\left(y^{*}\right)}}(t) \geq F_{x^{*}, y^{*}}(t) ; \forall t \in \mathbf{R}_{+}$, one gets for some $z_{x} \in\left[T x^{*}\right]_{\alpha\left(x^{*}\right)}$ and $z_{y} \in\left[T y^{*}\right]_{\alpha\left(y^{*}\right)}$ 
since $\left[T x^{*}\right]_{\alpha\left(x^{*}\right)}$ and $\left[T y^{*}\right]_{\alpha\left(y^{*}\right)}$ are members of $C B(X)$, that is, nonempty, closed and bounded sets,

$$
\begin{aligned}
& F_{y^{*},\left[T x^{*}\right]_{\alpha\left(x^{*}\right)}}(k t) \geq F_{x^{*},\left[T y^{*}\right]_{\alpha\left(y^{*}\right)}}(k t) \\
& =\min \left(F_{x^{*},\left[T y^{*}\right]_{\alpha\left(y^{*}\right)}}(k t), F_{y^{*},\left[T x^{*}\right]_{\alpha\left(x^{*}\right)}}(k t)\right) \\
& =\min \left(F_{x^{*}, z_{y}}(k t), F_{y^{*}, z_{x}}(k t)\right) \geq a_{1}\left(x^{*}, y^{*}, k t\right)
\end{aligned}
$$

$$
\begin{aligned}
& \cdot F_{x^{*},\left[T x^{*}\right]_{\alpha\left(x^{*}\right)}}(t)+a_{2}\left(x^{*}, y^{*}, k t\right) F_{y^{*},\left[T y^{*}\right]_{\alpha\left(y^{*}\right)}}(t) \\
& +a_{3}\left(x^{*}, y^{*}, k t\right) F_{x^{*}, y^{*}}(t) \geq\left(a_{1}\left(x^{*}, y^{*}, k t\right)\right. \\
& \left.+a_{2}\left(x^{*}, y^{*}, k t\right)+a_{3}\left(x^{*}, y^{*}, k t\right)\right) F_{x^{*}, y^{*}}(t)
\end{aligned}
$$

so that

$$
\begin{aligned}
& \min \left(F_{x^{*}, z_{y}}(k t), F_{y^{*}, z_{x}}(k t)\right) \geq\left(a_{1}\left(x^{*}, y^{*}, t\right)+a_{2}\left(x^{*}, y^{*}, t\right)+a_{3}\left(x^{*}, y^{*}, t\right)\right) F_{x^{*}, y^{*}}\left(k^{-1} t\right) \\
& \geq\left(a_{1}\left(x^{*}, y^{*}, t\right)+a_{2}\left(x^{*}, y^{*}, t\right)+a_{3}\left(x^{*}, y^{*}, t\right)\right) \Delta_{M}\left(F_{x^{*}, z_{y}}\left(\frac{k^{-1} t}{2}\right), F_{z_{y}, y^{*}}\left(\frac{k^{-1} t}{2}\right)\right) \\
& \geq \prod_{i=1}^{m}\left[a_{1}\left(x^{*}, y^{*}, k^{-i+1} t\right)+a_{2}\left(x^{*}, y^{*}, k^{-i+1} t\right)+a_{3}\left(x^{*}, y^{*}, k^{-i+1} t\right)\right] \Delta_{M}\left(F_{x^{*}, z_{y}}\left((2 k)^{-m} t\right), F_{z_{y}, y^{*}}\left((2 k)^{m} t\right)\right) \\
& \geq \lim _{n \rightarrow \infty}\left(\prod_{i=1}^{n}\left[a_{1}\left(x^{*}, y^{*}, k^{-i+1} t\right)+a_{2}\left(x^{*}, y^{*}, k^{-i+1} t\right)+a_{3}\left(x^{*}, y^{*}, k^{-i+1} t\right)\right]\right) \\
& \cdot \liminf _{n \rightarrow \infty} \Delta_{M}\left(F_{x^{*}, z_{y}}\left((2 k)^{-n} t\right), F_{z_{y}, y^{*}}\left((2 k)^{-n} t\right)\right) \\
& \geq \lim _{n \rightarrow \infty}\left(\prod_{i=1}^{n}\left[a_{1}\left(x^{*}, y^{*}, k^{-i+1} t\right)+a_{2}\left(x^{*}, y^{*}, k^{-i+1} t\right)+a_{3}\left(x^{*}, y^{*}, k^{-i+1} t\right)\right]\right) \\
& \cdot \Delta_{M}\left(F_{x^{*}, z_{y}}\left(\lim _{n \rightarrow \infty}(2 k)^{-n} t\right), F_{z_{y}, y^{*}}\left(\lim _{n \rightarrow \infty}(2 k)^{-n} t\right)\right) \\
& \left.=\lim _{n \rightarrow \infty}\left(\prod_{i=1}^{n}\left[a_{1}\left(x^{*}, y^{*}, k^{-i+1} t\right)+a_{2}\left(x^{*}, y^{*}, k^{-i+1} t\right)+a_{3}\left(x^{*}, y^{*}, k^{-i+1} t\right)\right]\right) H(+\infty)^{-}\right)=1 ; t \in \mathbf{R}_{+}, \forall m \in \mathbf{Z}_{+}
\end{aligned}
$$

and then $y^{*}=z_{x}, x^{*}=z_{y}\left(\left[T y^{*}\right]_{\alpha\left(y^{*}\right)} \cap\left[T x^{*}\right]_{\alpha\left(x^{*}\right)}\right)$ so that $\left[T y^{*}\right]_{\alpha\left(y^{*}\right)} \cap\left[T x^{*}\right]_{\alpha\left(x^{*}\right)}$ is nonempty. We can now assume that $F_{y^{*},\left[T x^{*}\right]_{\alpha\left(x^{*}\right)}}(k t) \leq F_{x^{*},\left[T y^{*}\right]_{\alpha\left(y^{*}\right)}}(k t) ; \forall t \in \mathbf{R}_{+}$. It is direct to prove in a close way to the above proof that $y^{*} \in\left[T y^{*}\right]_{\alpha\left(y^{*}\right)} \cap$ $\left[T x^{*}\right]_{\alpha\left(x^{*}\right)}$.

Remark 8. Note that a direct consequence of Theorem 7 , from the definition of the level sets, is that

$$
\begin{aligned}
& x^{*}, y^{*} \\
& \quad \in\left(\left(\bigcap_{\beta \in\left(0, \alpha\left(x^{*}\right)\right]}\left[T x^{*}\right]_{\beta}\right) \cap\left(\bigcap_{\beta \in\left(0, \alpha\left(y^{*}\right)\right]}\left[T y^{*}\right]_{\beta}\right)\right)
\end{aligned}
$$

if $x^{*} \in\left[T x^{*}\right]_{\alpha\left(x^{*}\right)}$ and $y^{*} \in\left[T y^{*}\right]_{\alpha\left(y^{*}\right)}$ are any probabilistic $\alpha\left(x^{*}\right)$ and $\alpha\left(y^{*}\right)$-fuzzy fixed points.

Remark 9. Note that corollaries to Theorem 7 can also be stated "mutatis-mutandis" under extended contractive conditions for probabilistic fuzzy fixed points to those given in Corollaries $3-5$.

Theorem 10. Consider a complete probabilistic metric space $\left(X, F, \Delta_{M}\right)$ under all the assumptions of Theorem 2 and conditions (1)-(3) where the contractive condition

$$
\begin{aligned}
H_{[T x]_{\alpha(x)},[T y]_{\alpha(y)}}(k t) \geq & a_{1}(x, y, k t) F_{x,[T x]_{\alpha(x)}}(t) \\
& +a_{2}(x, y, k t) F_{y,[T y]_{\alpha(y)}}(t) \\
& +a_{3}(x, y, k t) F_{x, y}(t)
\end{aligned}
$$

is extended to hold for any $x, y \in X$ with $a_{i}: X \times X \times \mathbf{R}_{0+} \rightarrow$ $[0,1]$ for $i=1,3 ; a_{2}: X \times X \times \mathbf{R}_{0+} \rightarrow[0,1)$.

Proof. Note, from Theorem 2, a sequence $\left\{x_{n}\right\} \subset X$ can be built being a (convergent) Cauchy sequence such that $\left\{x_{n}\right\} \rightarrow$ 
$x^{*}, x_{n+1}=T x_{n} \in\left[T x_{n}\right]_{\alpha\left(x_{n}\right)} ; \forall n \in \mathbf{Z}_{0+}$ for any given $x_{0} \in X$. Then,

$$
\begin{aligned}
& \lim _{n \rightarrow \infty} F_{x_{n}, T x_{n}}(t)=\lim _{n \rightarrow \infty} F_{x_{n}, x^{*}}(t)=1 ; \quad \forall t \in \mathbf{R}_{+}, \\
& \lim _{n \rightarrow \infty} F_{T x_{n}, x^{*}}(t)=1 ; \quad \forall t \in \mathbf{R}_{+}, \\
& \text {since } F_{T x_{n}, x^{*}}(t) \geq \Delta_{M}\left(F_{x^{*}, x_{n}}\left(\frac{t}{2}\right),\right. \\
& \left.\quad \Delta_{M}\left(F_{x_{n}, x_{n+1}}\left(\frac{t}{4}\right)\right), F_{T x_{n}, T x_{n}}\left(\frac{t}{4}\right)\right) \\
& >\min (1-\lambda, 1-\lambda, 1)=1-\lambda
\end{aligned}
$$

for any given $t \in \mathbf{R}_{+}, \lambda \in(0,1), n\left(\geq N_{0}\right) \in \mathbf{Z}_{0+}$, and $N_{0}=$ $N_{0}(\varepsilon, \lambda) \geq \max \left(N_{1}, N_{2}\right)$ such that

$$
\begin{aligned}
& F_{x^{*}, x_{n}}\left(\frac{t}{2}\right)>1-\lambda, \\
& \text { for } n\left(\geq N_{1}\right) \in \mathbf{Z}_{0+} \text { and some } N_{1}=N_{1}(\varepsilon, \lambda) \in \mathbf{Z}_{0+}, \\
& F_{x_{n+1}, x_{n}}\left(\frac{t}{4}\right)>1-\lambda,
\end{aligned}
$$

for $n\left(\geq N_{2}\right) \in \mathbf{Z}_{0+}$ and some $N_{2}=N_{2}(\varepsilon, \lambda) \in \mathbf{Z}_{0+}$,

since $F_{T x_{n}, T x_{n}}(t / 4)=1 ; \forall t \in \mathbf{R}_{+}, \forall n \in \mathbf{Z}_{0+}$ from property (1) of (3) for PM-spaces.

Theorem 11. Let $F(X)$ be the collection of all fuzzy sets in a $P M$-space $(X, \mathbf{F})$, where $X$ is a nonempty abstract set, and let $T: X \rightarrow F(X)$ be a fuzzy mapping. Assume that the following conditions are fulfilled:

(1) for each $x \in X$, there exists $\alpha(x) \in(0,1]$ such that $[T x]_{\alpha(x)}$ is a nonempty closed bounded subset of $X$, and each sequence $\left\{x_{n}\right\} \subset X$ of the form $x_{1} \in X$, $x_{n+1} \in\left[T x_{n}\right]_{\alpha\left(x_{n}\right)}$ with $\left[T x_{n}\right]_{\alpha\left(x_{n}\right)} \in C B(X) ; \forall n \in \mathbf{Z}_{0+}$ which satisfies the following contractive constraint for some real constant $k \in(0,1)$ :

$$
\begin{aligned}
H_{[T x]_{\alpha(x),[T y]_{\alpha(y)}}}(k t) \geq & a_{1} F_{x,[T x]_{\alpha(x)}}(t)+a_{2} F_{x,[T y]_{\alpha(y)}}(t) \\
& +a_{3} F_{y,[T x]_{\alpha(x)}}(t) \\
& +a_{4} F_{y,[T y]_{\alpha(y)}}(t)+a_{5} F_{x, y}(t) ;
\end{aligned}
$$

$\forall x \in X, \forall y \in[T x]_{\alpha(x)}$, where $a_{i} \in[0,1]$ for $i=$ $1,3,4,5 ; a_{2}: X \times X \times \mathbf{R}_{0+} \rightarrow[0,1)$,

(2)

$0<a=\sum_{i=1}^{5} a_{i} \leq 1$

$\forall t \in \mathbf{R}_{0+}, \forall x \in X, \forall y \in[T x]_{\alpha(x)} \subset C B(X)$,

(3)

$$
\begin{aligned}
& \lim _{N \rightarrow \infty} \prod_{i=0}^{N}\left[\frac{a_{1}\left(x_{i+1}, x_{i+2}, k^{-i+1} t\right)+a_{3}\left(x_{i+1}, x_{i+2}, k^{-i+1} t\right)}{1-a_{2}\left(x_{i+1}, x_{i+2}, k^{-i+1} t\right)}\right] \\
& \quad=1 ; \quad x_{n+1} \in\left[T x_{n}\right]_{\alpha\left(x_{n}\right)} \in C B(X), \forall t \in \mathbf{R}_{+}, \forall n \in \mathbf{Z}_{0+.}
\end{aligned}
$$

Then, a sequence $\left\{x_{n}\right\}$ may be constructed for any given arbitrary $x_{1}=x \in X$ such that $x_{n+1} \in\left[T x_{n}\right]_{\alpha\left(x_{n}\right)} \in C B(X)$, with $\left\{\alpha\left(x_{n}\right)\right\} \subseteq(0,1]$ satisfying $\lim _{n \rightarrow \infty} F_{x_{n}, x_{n+1}}(t)=1 ; \forall t \in$ $\mathbf{R}_{+}$.

If, in addition, $(X, \mathbf{F})$ is endowed with the minimum triangular norm $\Delta_{M}:[0,1] \times[0,1] \rightarrow[0,1]$ and $\left(X, F, \Delta_{M}\right)$ is a complete Menger space then each of such sequences $\left\{x_{n}\right\}$ is a Cauchy sequence which is convergent to a probabilistic $\alpha^{*}$ fuzzy fixed point $x^{*}$ of $T: X \rightarrow F(X)$.

Proof. Since $[T x]_{\alpha(x)},[T y]_{\alpha(y)} \subset X$,

$$
\begin{aligned}
& \max \left(F_{x,[T y]_{\alpha(y)}}(k t), F_{y,[T x]_{\alpha(x)}}(k t)\right) \\
& \geq \min \left(F_{x,[T y]_{\alpha(y)}}(k t), F_{y,[T x]_{\alpha(x)}}(k t)\right) \\
& \min _{z \in[T x]_{\alpha(x)}, \omega \in[T y]_{\alpha(y)}}\left(F_{z,[T y]_{\alpha(y)}}(k t), F_{\omega,[T x]_{\alpha(x)}}(k t)\right) \\
& =H\left(F_{[T x]_{\alpha(x)}}(k t),[T y]_{\alpha(y)}(k t)\right) \\
& \geq a_{1} F_{x,[T x]_{\alpha(x)}}(t)+a_{2} F_{x,[T y]_{\alpha(y)}}(t)+a_{3} F_{y,[T x]_{\alpha(x)}}(t) \\
& +a_{4} F_{y,[T y]_{\alpha(y)}}(t)+a_{5} F_{x, y}(t)
\end{aligned}
$$

$\forall t \in \mathbf{R}_{+}, \forall x, y \in X$.

Now for any given $x, y \in X$. Then, the following cases can occur:

(a) If $F_{x,[T y]_{\alpha(y)}}(k t) \geq F_{y,[T x]_{\alpha(x)}}(k t), F_{x,[T x]_{\alpha(x)}}(t) \geq$ $F_{y,[T y]_{\alpha(y)}}(t)$, and $F_{y,[T y]_{\alpha(y)}}(t) \geq F_{x, y}(t) ; \forall t \in \mathbf{R}_{+}$then

$F_{y,[T x]_{\alpha(x)}}(k t)$

$$
\begin{aligned}
\geq & a_{1} F_{x,[T x]_{\alpha(x)}}(t)+\left(a_{2}+a_{3}\right) F_{y,[T x]_{\alpha(x)}}(t) \\
& +a_{4} F_{y,[T y]_{\alpha(y)}}(t)+a_{5} F_{x, y}(t) ; \quad \forall t \in \mathbf{R}_{+},
\end{aligned}
$$

$$
\left(1-a_{2}-a_{3}\right) F_{y,[T x]_{\alpha(x)}}(k t)
$$

$$
\begin{aligned}
& \geq a_{1} F_{x,[T x]_{\alpha(x)}}(t)+a_{4} F_{y,[T y]_{\alpha(y)}}(t)+a_{5} F_{x, y}(t) \\
& \geq\left(a_{1}+a_{4}\right) F_{y,[T y]_{\alpha(y)}}(t)+a_{5} F_{x, y}(t) \\
& \geq\left(a_{1}+a_{4}+a_{5}\right) F_{x, y}(t) ; \quad \forall t \in \mathbf{R}_{+}
\end{aligned}
$$

so that

$$
F_{x,[T y]_{\alpha(y)}}(k t) \geq F_{y,[T x]_{\alpha(x)}}(k t) \geq \frac{a_{1}+a_{4}+a_{5}}{1-a_{2}-a_{3}} F_{x, y}(t) ;
$$


(b) If $F_{x,[T y]_{\alpha(y)}}(k t) \geq F_{y,[T x]_{\alpha(x)}}(k t), F_{x,[T x]_{\alpha(x)}}(t) \geq$ $F_{y,[T y]_{\alpha(y)}}(t)$, and $F_{y,[T y]_{\alpha(y)}}(t) \leq F_{x, y}(t) ; \forall t \in \mathbf{R}_{+}$then

$$
\begin{aligned}
F_{x,[T y]_{\alpha(y)}}(t) \geq & F_{y,[T x]_{\alpha(x)}}(t) \\
\geq & \left(a_{2}+a_{3}\right) F_{y,[T x]_{\alpha(x)}}(t) \\
& +\left(a_{1}+a_{4}+a_{5}\right) F_{y,[T y]_{\alpha(y)}}(t) ;
\end{aligned}
$$

$\forall t \in \mathbf{R}_{+}$

so that

$$
\begin{aligned}
F_{x,[T y]_{\alpha(y)}}(k t) & \geq F_{y,[T x]_{\alpha(x)}}(k t) \\
& \geq \frac{a_{1}+a_{4}+a_{5}}{1-a_{2}-a_{3}} F_{y,[T y]_{\alpha(y)}}(t) ; \quad \forall t \in \mathbf{R}_{+} .
\end{aligned}
$$

(c) If $F_{x,[T y]_{\alpha(y)}}(k t) \geq F_{y,[T x]_{\alpha(x)}}(k t), F_{x,[T x]_{\alpha(x)}}(t) \leq$ $F_{y,[T y]_{\alpha(y)}}(t)$, and $F_{y,[T y]_{\alpha(y)}}(t) \geq F_{x, y}(t) ; \forall t \in \mathbf{R}_{+}$then

$$
\begin{aligned}
& \left(1-a_{2}-a_{3}\right) F_{x,[T y]_{\alpha(y)}}(t) \geq\left(1-a_{2}-a_{3}\right) F_{y,[T x]_{\alpha(x)}}(t) \\
& \quad \geq a_{1} F_{x,[T x]_{\alpha(x)}}(t)+a_{4} F_{y,[T y]_{\alpha(y)}}(t)+a_{5} F_{x, y}(t) \\
& \quad \geq \max \left[\left(a_{1}+a_{4}\right) F_{x,[T x]_{\alpha(x)}}(t)\right. \\
& \left.\quad+a_{5} F_{x, y}(t), a_{1} F_{x,[T x]_{\alpha(x)}}(t)+\left(a_{4}+a_{5}\right) F_{x, y}(t)\right] \\
& \geq\left(a_{1}+a_{4}+a_{5}\right) \min \left(F_{x,[T x]_{\alpha(x)}}(t), F_{x, y}(t)\right)
\end{aligned}
$$$$
\forall t \in \mathbf{R}_{+}
$$

so that

$$
\begin{aligned}
& F_{x,[T y]_{\alpha(y)}}(k t) \geq F_{y,[T x]_{\alpha(x)}}(k t) \\
& \quad \geq \frac{a_{1}+a_{4}+a_{5}}{1-a_{2}-a_{3}} \min \left(F_{x,[T x]_{\alpha(x)}}(t), F_{x, y}(t)\right) ;
\end{aligned}
$$

$\forall t \in \mathbf{R}_{+}$.

(d) If $F_{x,[T y]_{\alpha(y)}}(k t) \geq F_{y,[T x]_{\alpha(x)}}(k t), F_{x,[T x]_{\alpha(x)}}(t) \leq$ $F_{y,[T y]_{\alpha(y)}}(t)$, and $F_{y,[T y]_{\alpha(y)}}(t) \leq F_{x, y}(t) ; \forall t \in \mathbf{R}_{+}$then

$$
\begin{aligned}
& F_{x,[T y]_{\alpha(y)}}(k t) \geq F_{y,[T x]_{\alpha(x)}}(k t) \\
& \geq\left(a_{1}+a_{4}\right) F_{x,[T x]_{\alpha(x)}}(t)+\left(a_{2}+a_{3}\right) F_{y,[T x]_{\alpha(x)}}(t) \\
& \quad+a_{5} F_{x, y}(t) ; \quad \forall t \in \mathbf{R}_{+}, \\
& F_{x,[T y]_{\alpha(y)}}(k t) \geq F_{y,[T x]_{\alpha(x)}}(k t) \\
& \geq \frac{a_{1}+a_{4}+a_{5}}{1-a_{2}-a_{3}} \min \left(F_{x,[T x]_{\alpha(x)}}(t), F_{y,[T y]_{\alpha(y)}}(t)\right) \\
& =\frac{a_{1}+a_{4}+a_{5}}{1-a_{2}-a_{3}} F_{x,[T x]_{\alpha(x)}}(t) ; \quad \forall t \in \mathbf{R}_{+} .
\end{aligned}
$$

(e) If $F_{x,[T y]_{\alpha(y)}}(k t) \leq F_{y,[T x]_{\alpha(x)}}(k t), F_{x,[T x]_{\alpha(x)}}(t) \geq$ $F_{y,[T y]_{\alpha(y)}}(t)$, and $F_{y,[T y]_{\alpha(y)}}(t) \geq F_{x, y}(t) ; \forall t \in \mathbf{R}_{+}$then

$$
\begin{array}{r}
F_{y,[T x]_{\alpha(x)}}(k t) \geq F_{x,[T y]_{\alpha(y)}}(k t) \geq \frac{a_{1}+a_{4}+a_{5}}{1-a_{2}-a_{3}} F_{x, y}(t) ; \\
\forall t \in \mathbf{R}_{+} .
\end{array}
$$

(f) If $F_{x,[T y]_{\alpha(y)}}(k t) \leq F_{y,[T x]_{\alpha(x)}}(k t), F_{x,[T x]_{\alpha(x)}}(t) \geq$ $F_{y,[T y]_{\alpha(y)}}(t)$, and $F_{y,[T y]_{\alpha(y)}}(t) \leq F_{x, y}(t) ; \forall t \in \mathbf{R}_{+}$then

$$
\begin{aligned}
F_{y,[T x]_{\alpha(x)}}(t) & \geq F_{x,[T y]_{\alpha(y)}}(t) \\
& \geq \frac{a_{1}+a_{4}+a_{5}}{1-a_{2}-a_{3}} F_{y,[T y]_{\alpha(y)}}(t) ; \quad \forall t \in \mathbf{R}_{+} .
\end{aligned}
$$

(g) If $F_{x,[T y]_{\alpha(y)}}(k t) \leq F_{y,[T x]_{\alpha(x)}}(k t), F_{x,[T x]_{\alpha(x)}}(t) \leq$ $F_{y,[T y]_{\alpha(y)}}(t)$, and $F_{y,[T y]_{\alpha(y)}}(t) \geq F_{x, y}(t) ; \forall t \in \mathbf{R}_{+}$then

$$
\begin{aligned}
F_{y,[T x]_{\alpha(x)}}(k t) \geq F_{x,[T y]_{\alpha(y)}}(k t) \\
\quad \geq \frac{a_{1}+a_{4}+a_{5}}{1-a_{2}-a_{3}} \min \left(F_{x,[T x]_{\alpha(x)}}(t), F_{x, y}(t)\right) ;
\end{aligned}
$$

$\forall t \in \mathbf{R}_{+}$.

(h) If $F_{x,[T y]_{\alpha(y)}}(k t) \leq F_{y,[T x]_{\alpha(x)}}(k t), F_{x,[T x]_{\alpha(x)}}(t) \leq$ $F_{y,[T y]_{\alpha(y)}}(t)$, and $F_{y,[T y]_{\alpha(y)}}(t) \geq F_{x, y}(t) ; \forall t \in \mathbf{R}_{+}$then

$$
F_{y,[T x]_{\alpha(x)}}(k t) \geq F_{x,[T y]_{\alpha(y)}}(k t)
$$

$$
\begin{aligned}
& \geq \frac{a_{1}+a_{4}+a_{5}}{1-a_{2}-a_{3}} \min \left(F_{x,[T x]_{\alpha(x)}}(t), F_{y,[T y]_{\alpha(y)}}(t)\right) \\
& =\frac{a_{1}+a_{4}+a_{5}}{1-a_{2}-a_{3}} F_{x,[T x]_{\alpha(x)}}(t) ; \quad \forall t \in \mathbf{R}_{+} .
\end{aligned}
$$

Now, take $x_{1} \in X, x_{2}=y \in[T x]_{\alpha(x)}$, and any $z=x_{3} \epsilon$ $[T y]_{\alpha(y)}$ such that $F_{x, y}(t)=F_{x,[T x]}(t)$. Then, one gets for Cases (a)-(h)

$$
F_{x_{2}, x_{3}}(t) \geq \frac{a_{1}+a_{4}+a_{5}}{1-a_{2}-a_{3}} F_{x_{1}, x_{2}}\left(k^{-1} t\right)=F_{x_{1}, x_{2}}\left(k^{-1} t\right)
$$

and we can construct a sequence $\left\{x_{n}\right\} \subset X$ with $x_{1}=x \in$ $X$ arbitrary, $x_{n+1} \in\left[T x_{n}\right]_{\alpha\left(x_{n}\right)} \in C B(X)$ for some sequence $\left\{\alpha\left(x_{n}\right)\right\} \subset(0,1]$, such that since $\left(a_{1}+a_{4}+a_{5}\right) /\left(1-a_{2}-a_{3}\right)=1$, one gets proceeding recursively:

$$
\begin{aligned}
F_{x_{n+1}, x_{n}}(t) & \geq \frac{a_{1}+a_{4}+a_{5}}{1-a_{2}-a_{3}} F_{x_{1}, x_{2}}\left(k^{-1} t\right) \\
& \geq F_{x_{1}, x_{2}}\left(k^{-n+1} t\right) ;
\end{aligned}
$$

$\forall n(\geq 2) \in \mathbf{Z}_{+} ; \forall t \in \mathbf{R}_{+}$

so that $\lim _{n \rightarrow \infty} F_{x_{n+1}, x_{n}}(t)=1 ; \forall t \in \mathbf{R}_{+}$. 
Remark 12. Extensions of Theorem 11 are direct for the case when the subsequent contractive condition holds instead of (48):

$$
\begin{array}{r}
H\left(F_{[T x]_{\alpha(x)}}(k t),[T y]_{\alpha(y)}(k t)\right) \\
\geq \min \left(1, a_{1} F_{x,[T x]_{\alpha(x)}}(t)+a_{2} F_{x,[T y]_{\alpha(y)}}(t)\right. \\
\left.+a_{3} F_{y,[T x]_{\alpha(x)}}(t)+a_{4} F_{y,[T y]_{\alpha(y)}}(t)+a_{5} F_{x, y}(t)\right) ; \\
\forall x, y \in X, \forall t \in \mathbf{R}_{+} .
\end{array}
$$

Extensions of Theorem 11 and its variant of Remark 12 to the light of Theorems 2 and 10 are direct concerning the case when the coefficients of the respective contractive condition are functions $a_{i}: X \times X \times \mathbf{R}_{0+} \rightarrow[0,1]$ for $i=1,3,4,5$; $a_{2}: X \times X \times \mathbf{R}_{0+} \rightarrow[0,1)$. Also, close examples to Example 6 can be given for the more general contractive conditions of this section.

\section{Conflict of Interests}

The author declares that he has no conflict of interests.

\section{Acknowledgments}

The author is very grateful to the Spanish Government for Grant DPI2012-30651 and to the Basque Government and UPV/EHU for Grants IT378-10, SAIOTEK S-PE13UN039, and UFI 2011/07.

\section{References}

[1] S. Heilpern, "Fuzzy mappings and fixed point theorem," Journal of Mathematical Analysis and Applications, vol. 83, no. 2, pp. 566-569, 1981.

[2] M. A. Ahmed, "Fixed point theorems in fuzzy metric spaces," Journal of the Egyptian Mathematical Society, vol. 22, no. 1, pp. 59-62, 2014.

[3] A. Chitra and P. V. Subrahmanyam, "Fuzzy sets and fixed points," Journal of Mathematical Analysis and Applications, vol. 124, no. 2, pp. 584-590, 1987.

[4] M. Grabiec, "Fixed points in fuzzy metric spaces," Fuzzy Sets and Systems, vol. 27, no. 3, pp. 385-389, 1988.

[5] B. Singh, S. Jain, and S. Jain, "Generalized theorems on fuzzy metric spaces," Southeast Asian Bulletin of Mathematics, vol. 31, no. 5, pp. 963-978, 2007.

[6] A. Azam and I. Beg, "Common fuzzy fixed points for fuzzy mappings," Fixed Point Theory and Applications, vol. 2013, article 14, 2013.

[7] Y. J. Cho, H. K. Pathak, S. M. Kang, and J. S. Jung, "Common fixed points of compatible maps of type $(\beta)$ on fuzzy metric spaces," Fuzzy Sets and Systems, vol. 93, no. 1, pp. 99-111, 1998.

[8] D. Qiu and L. Shu, "Supremum metric on the space of fuzzy sets and common fixed point theorems for fuzzy mappings," Information Sciences, vol. 178, no. 18, pp. 3595-3604, 2008.

[9] M. Abbas, I. Altun, and D. Gopal, "Common fixed point theorems for non compatible mappings in fuzzy metric spaces,"
Bulletin of Mathematical Analysis and Applications, vol. 1, no. 2, pp. 47-56, 2009.

[10] S. Phiangsungnoen, W. Sintunavarat, and P. Kumam, "Common $\alpha$-fuzzy fixed point theorems for fuzzy mappings via $\beta_{F^{-}}$ admissible pair," Journal of Intelligent and Fuzzy Systems, vol. 27, no. 5, pp. 2463-2472, 2014.

[11] A. Jain, A. Sharma, V. Gupta, and A. Tiwari, "Common fixed point theorem in fuzzy metric space with special reference to occasionally weakly compatible mappings," Journal of Mathematics and Computer Science, vol. 4, no. 2, pp. 374-383, 2014.

[12] D. Turkoglu and B. E. Rhoades, "A fixed fuzzy point for fuzzy mapping in complete metric spaces," Mathematical Communications, vol. 10, pp. 115-121, 2005.

[13] K. Singh Sisodia, D. Singh, and M. S. Rathore, "A common fixed point theorem for subcompatibility and occasionally weak compatibility in intuitionistic fuzzy metric spaces," General Mathematics Notes, vol. 21, no. 1, pp. 73-85, 2014.

[14] S. Manro, H. Bouharjera, and S. Singh, "A common fixed point theorem in intuitionistic fuzzy metric space by using sub-compatible maps," International Journal of Contemporary Mathematical Sciences, vol. 5, no. 55, pp. 2699-2707, 2010.

[15] M. De la Sen and A. Ibeas, "Properties of convergence of a class of iterative processes generated by sequences of self-mappings with applications to switched dynamic systems," Journal of Inequalities and Applications, vol. 2014, article 498, 2014.

[16] M. De la Sen and E. Karapinar, "On a cyclic Jungck modified TS-iterative procedure with application examples," Applied Mathematics and Computation, vol. 233, pp. 383-397, 2014.

[17] M. De la Sen, "About robust stability of caputo linear fractional dynamic systems with time delays through fixed point theory," Fixed Point Theory and Applications, vol. 2011, Article ID 867932, 2011.

[18] V. Berinde and M. Păcurar, "The role of the Pompeiu-Hausdorff metric in fixed point theory," Creative Mathematics and Informatics, vol. 22, no. 2, pp. 143-150, 2013.

[19] S. Karpagam and S. Agrawal, "Best proximity point theorems for p-cyclic Meir-Keeler contractions," Fixed Point Theory and Applications, vol. 2009, article 197308, 9 pages, 2009.

[20] M. De la Sen, "Linking contractive self-mappings and cyclic meir-keeler contractions with kannan self-mappings," Fixed Point Theory and Applications, vol. 2010, Article ID 572057, 2010.

[21] C. Di Bari, T. Suzuki, and C. Vetro, "Best proximity points for cyclic Meir-Keeler contractions," Nonlinear Analysis: Theory, Methods \& Applications, vol. 69, no. 11, pp. 3790-3794, 2008.

[22] S. Rezapour, M. Derafshpour, and N. Shahzad, "On the existence of best proximity points of cyclic contractions," Advances in Dynamical Systems and Applications, vol. 6, no. 1, pp. 33-40, 2011.

[23] M. A. Al-Thagafi and N. Shahzad, "Convergence and existence results for best proximity points," Nonlinear Analysis: Theory, Methods \& Applications, vol. 70, no. 10, pp. 3665-3671, 2009.

[24] M. Derafshpour, S. Rezapour, and N. Shahzad, "Best proximity points of cyclic $\varphi$-contractions on reflexive Banach spaces," Fixed Point Theory and Applications, vol. 2010, Article ID 946178, 7 pages, 2010.

[25] B. S. Choudhury, K. Das, and S. K. Bhandari, "Cyclic contraction result in 2-Menger space," Bulletin of International Mathematical Virtual Institute, vol. 2, no. 1, pp. 223-234, 2012.

[26] I. Beg and M. Abbas, "Fixed points and best approximation in menger convex metric spaces," Archivum Mathematicum, vol. 41, no. 4, pp. 389-397, 2005. 
[27] I. Beg, A. Latif, and M. Abbas, "Coupled fixed points of mixed monotone operators on probabilistic Banach spaces," Archivum Mathematicum, vol. 37, no. 1, pp. 1-8, 2001.

[28] M. De la Sen and E. Karapınar, "Some results on best proximity points of cyclic contractions in probabilistic metric spaces," Journal of Function Spaces, vol. 2015, Article ID 470574, 11 pages, 2015.

[29] M. De la Sen, R. P. Agarwal, and A. Ibeas, "Results on proximal and generalized weak proximal contractions including the case of iteration-dependent range sets," Fixed Point Theory and Applications, vol. 2014, article 169, 2014.

[30] M. Gabeleh, "Best proximity point theorems via proximal non self-mapping," Journal of Optimization Theory and Applications, vol. 164, no. 2, pp. 565-576, 2015.

[31] L. X. Wang, Adaptive Fuzzy Systems and Control: Design and Stability Analysis, Prentice-Hall, Englewood Cliffs, NJ, USA, 1994.

[32] M. De la Sen, A. F. Roldán, and R. P. Agarwal, "On contractive cyclic fuzzy maps in metric spaces and some related results on fuzzy best proximity points and fuzzy fixed points," Fixed Point Theory and Applications, vol. 2015, article 103, 2015.

[33] E. Pap, O. Hadžić, and R. Mesiar, "A fixed point theorem in probabilistic metric spaces and an application," Journal of Mathematical Analysis and Applications, vol. 202, no. 2, pp. 433449, 1996.

[34] V. M. Sehgal and A. T. Bharucha-Reid, "Fixed points of contraction mappings on probabilistic metric spaces," Theory of Computing Systems, vol. 6, no. 1, pp. 97-102, 1972.

[35] M. De la Sen, S. Alonso-Quesada, and A. Ibeas, "On the asymptotic hyperstability of switched systems under integraltype feedback regulation Popovian constraints," IMA Journal of Mathematical Control and Information, vol. 32, no. 2, pp. 359386, 2015.

[36] B. Schweizer and A. Sklar, Probabilistic Metric Spaces, NorthHolland Publishing, Amsterdam, The Netherlands, 1983.

[37] B. Schweizer and A. Sklar, "Statistical metric spaces," Pacific Journal of Mathematics, vol. 10, no. 1, pp. 313-334, 1960.

[38] M. De la Sen and A. Ibeas, "On the global stability of an iterative scheme in a probabilistic Menger space," Journal of Inequalities and Applications, vol. 2015, article 243, 2015. 


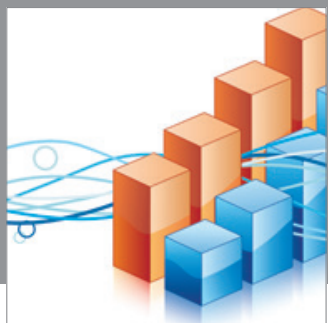

Advances in

Operations Research

mansans

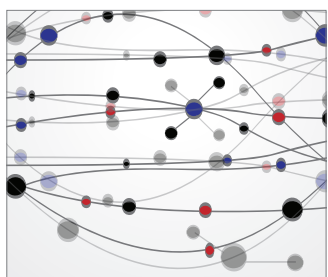

The Scientific World Journal
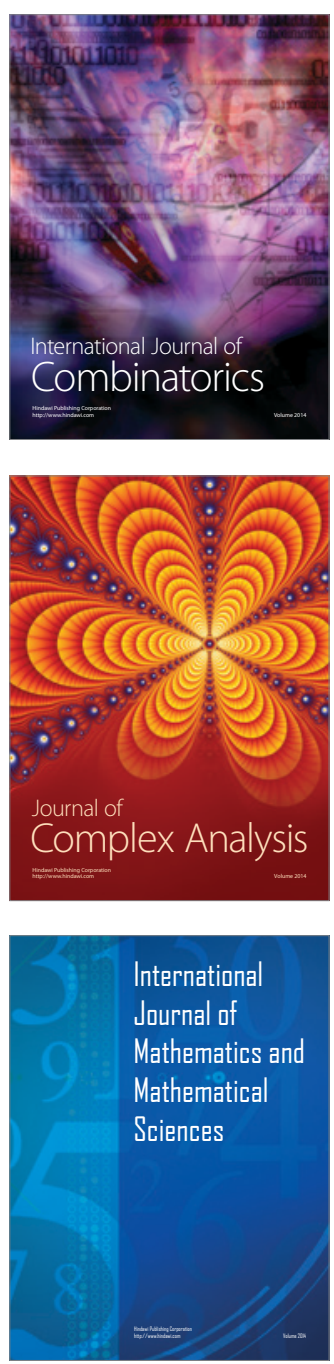
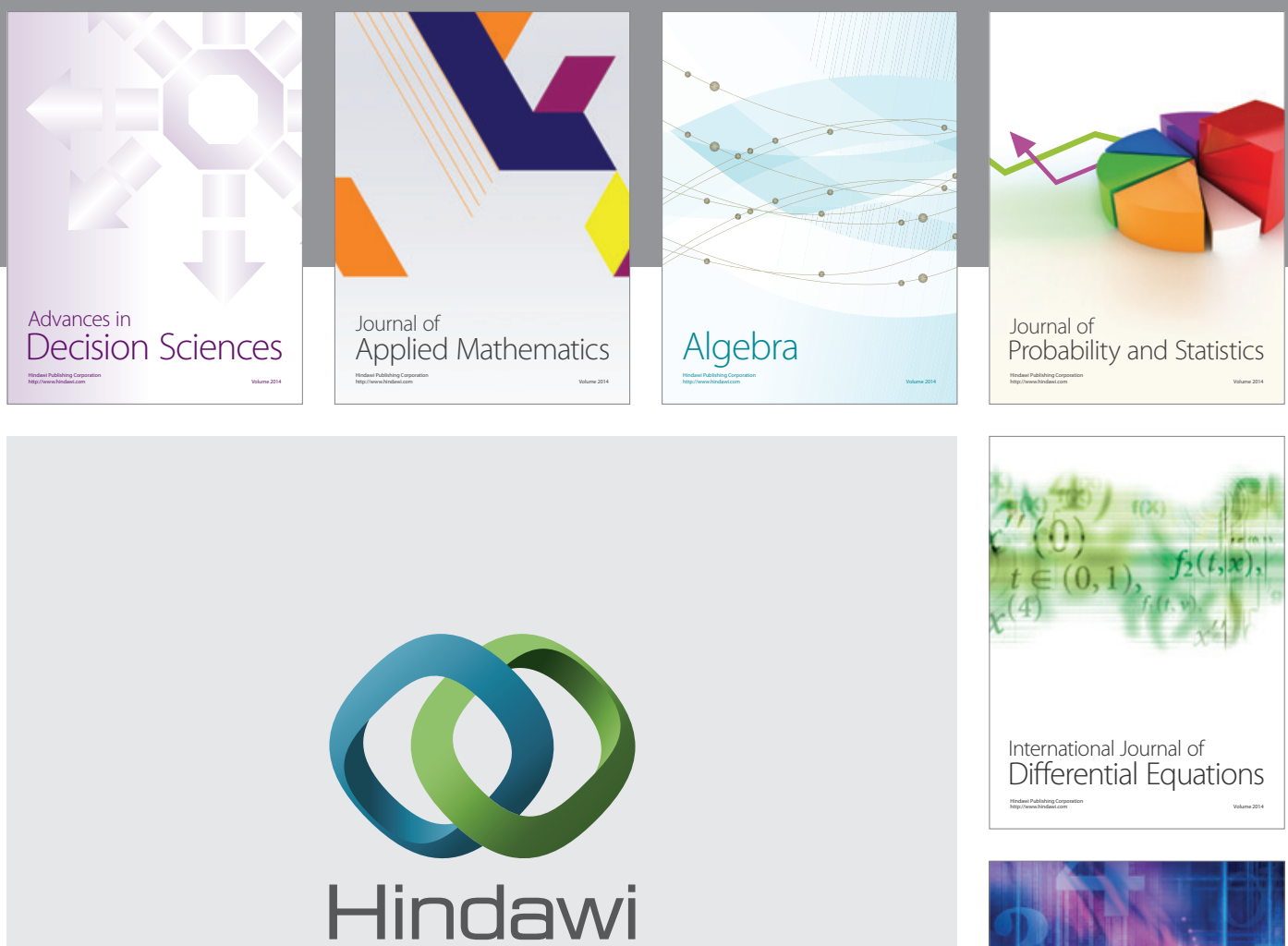

Submit your manuscripts at http://www.hindawi.com
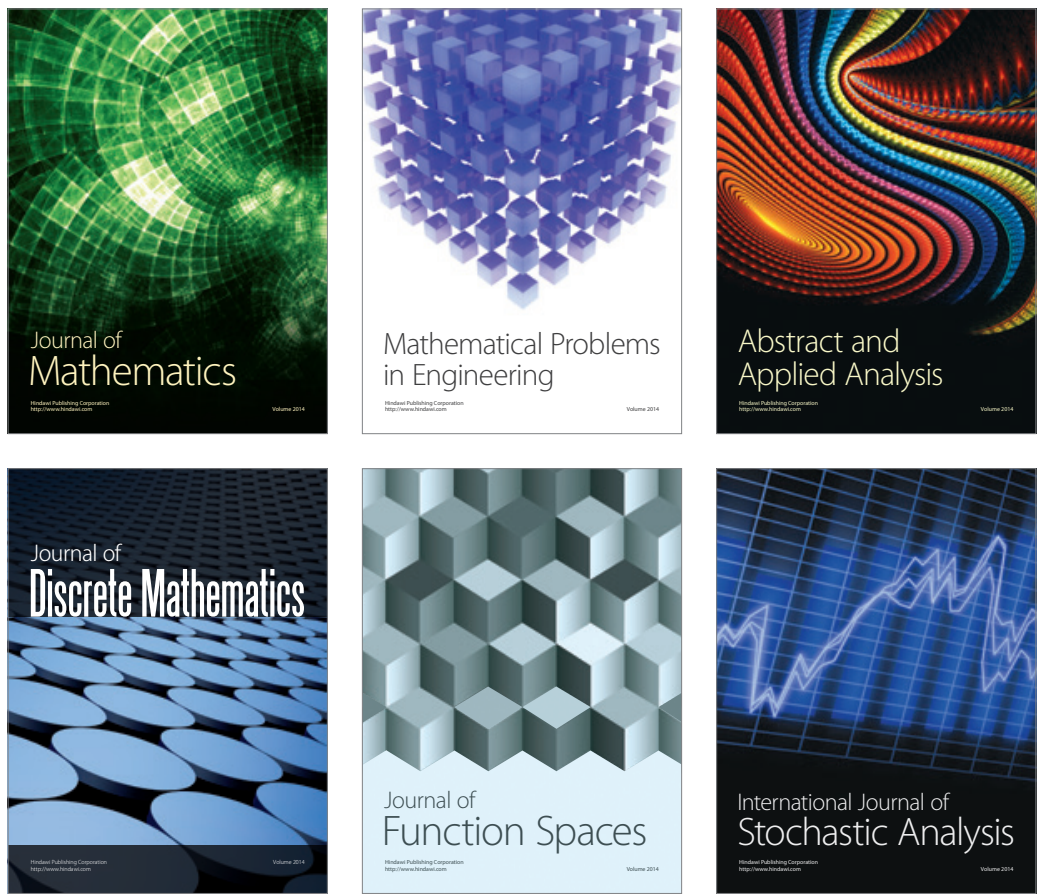

Journal of

Function Spaces

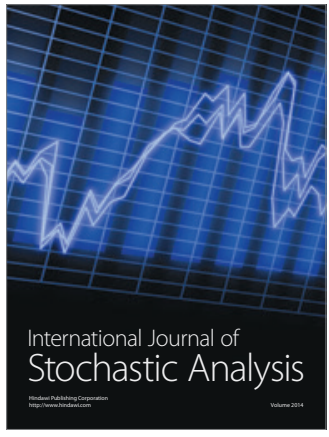

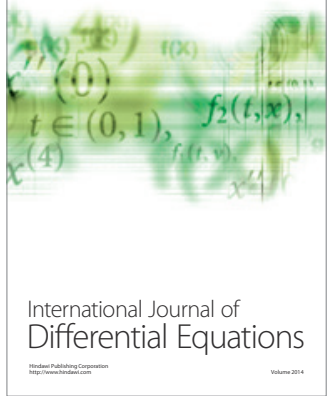
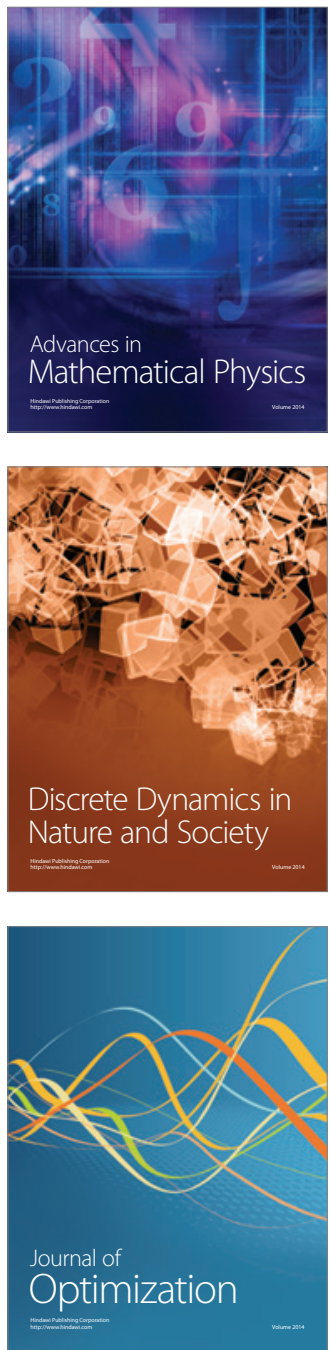